Article

\title{
In the Eyes of the Beholder: The Effect of the Perceived Authenticity of Sanfang Qixiang in Fuzhou, China, among Locals and Domestic Tourists
}

\author{
Gyehee Lee ${ }^{1} \mathbb{D}$, Xiao Lin ${ }^{1}$, Yunseon Choe ${ }^{2,3, *}$ and Wenya Li ${ }^{4}$ \\ 1 Department of Tourism, Kyung Hee University, 26 Kyungheedae-ro, Hoegi-dong, Dongdaemun-gu, \\ Seoul 02447, Korea; ghlee@khu.ac.kr (G.L.); kayxiao1106@126.com (X.L.) \\ 2 School of Community Resources and Development, Watts College of Public Service and \\ Community Solutions, Arizona State University, 411 N. Central Avenue, Phoenix, AZ 85004, USA \\ 3 Department of Tourism Development and Management, The Hainan University-Arizona State University \\ Joint International Tourism College, Hainan University, 58 Renmin Road, Haikou 570004, China \\ 4 School of Innovation, Entrepreneurship, and Creation, Sanming University, 25, Jingdong Road, \\ Sanming 365004, China; wenyasmail@khu.ac.kr \\ * Correspondence: yunseon.Choe@asu.edu
}

Citation: Lee, G.; Lin, X.; Choe, Y.; Li, $W$. In the Eyes of the Beholder: The Effect of the Perceived Authenticity of Sanfang Qixiang in Fuzhou, China, among Locals and Domestic Tourists. Sustainability 2021, 13, 12353. https:/ / doi.org/10.3390/su132212353

Academic Editors: Francesca Di Turo and Laura Medeghini

Received: 3 October 2021

Accepted: 2 November 2021

Published: 9 November 2021

Corrected: 23 August 2022

Publisher's Note: MDPI stays neutral with regard to jurisdictional claims in published maps and institutional affiliations.

Copyright: (C) 2021 by the authors. Licensee MDPI, Basel, Switzerland. This article is an open access article distributed under the terms and conditions of the Creative Commons Attribution (CC BY) license (https:/ / creativecommons.org/licenses/by/ $4.0 /)$.

\begin{abstract}
Many historic and cultural heritage destinations have faced queries about authentic travel experiences and crises of commoditization related to tourism products. This study is based on the dyadic function of heritage destinations for both locals and domestic tourists: heritage as a spatialtemporal object for tourists, using authenticity as a theoretical framework. It examined the (1) effects of cultural motivations and prior knowledge on both object-based and existential authenticities, (2) effects of authenticity on destination experiences, and (3) moderating role of residential status on the relationship between authenticity and destination experience. The data were collected from 173 locals and 159 domestic tourists on site in the Sanfang Qixiang tourist district and analyzed using the SEM technique. The results indicated that cultural motivation and prior knowledge had significant effects on authenticity; however, only existential authenticity enhanced the destination experience, whereas object-based authenticity did not have an effect on the destination experience. In addition, residential status had a key moderating function in the relationship between the perception of authenticity and the destination experience. This study contributes to the literature by integrating the mutual gaze into heritage tourism literature and emphasizing the importance of a balance between authenticity and commoditization in heritage destination development in Asia. The findings hold some practical implications for the development of balanced management strategies to minimize potential conflicts and maximize user satisfaction with heritage tourism.
\end{abstract}

Keywords: authenticity; commoditization; mutual gaze; locals and tourists; heritage tourism; cultural motivation; prior knowledge; tourist experience

\section{Introduction}

China is a country rich in cultural heritage; however, cultural heritage destinations, historical events, and modern development in the names of globalization and urbanization have gradually put this rich heritage under threat of debasement and loss of originality due to the creation of tourism areas [1]. Tourist destinations in China, such as Lijiang ancient town [2], Phoenix ancient town [3], and Zhouzhuang [4], have experienced varying degrees of commoditization. Facing the seduction of big and quick financial returns, many heritage tourism destinations have experienced changes and threats. Unfortunately, the Sanfang Qixiang (English: Three Lanes and Seven Alleys) in Fuzhou seems to be trapped in a similar development dilemma [5]. As this area was restored, the original locals moved out, ancient houses were remodeled into modern accommodations, and modern cinemas 
were built, causing discussions related to the authenticity of Sanfang Qixiang to occur (see Appendix A).

Discussions of authenticity had attracted attention from various fields before MacCannell [6] transferred this idea to the field of tourism. The complexity of authenticity extends it from being a simple, museum-linked objective [7] to having a variety of usages related to immaterial subjects and people. Considerable debates and arguments about the contested concept of authenticity in the current research, such as on pseudo-events [8], backstage [6], emergent authenticity [9], tourist gaze [10], and mutual gaze [11], have occurred. The inspiration for the present study stems from the concept of the mutual gaze of tourists to locals, locals to tourists, and among the tourists themselves so as to take into account the local-tourist interaction [11]. How do tourists and locals perceive authenticity differently in terms of the complex aspect of the destination experience [12]? Thus, it is important to identify the moderating role of residential status in the relationship between authenticity and destination experience, as differences exist in regard to perceptions of authenticity between locals and domestic tourists.

Heritage tourism is an inevitable topic in tourism research, and studies on heritage tourism include early popular subjects such as museums and historical buildings and, later, other intangible heritage assets, including festivals and artifacts. Disputes around heritage tourism definitions have occurred since the 2000s [13,14]. This dispute and discussions related to heritage management and heritage tourism have occupied a large percentage of the literature in this field $[13,15]$.

Within the heritage tourism literature, a research gap exists concerning locals' and tourists' perceptions of authenticity in Asia. Whereas authenticity has been explored as a significant element of the tourist experience, only a few quantitative studies have sought to compare the perceptions of authenticity of visitors and residents in China [12]. Even though research on residents' perceptions of authenticity may be critical to the tourism industry, which "uses the community as a resource, sells it as a product, and, in the process, affects the lives of everyone" [16] (p. 97), limited research has explored the perceptions of authenticity of those individuals who live in tourist destinations. Thus, a better understanding of the residents' perceptions of their areas is meaningful because their satisfaction is closely connected to tourists' experiences and satisfaction $[12,17,18]$.

First, the majority of the literature in this area centers on heritage protection, resource management, and sustainable development $[19,20]$. Studies on tourism in Sanfang Qixiang and the area's authenticity have been limited.

Second, in Western-centric heritage tourism studies, or in the newly arisen Asian context, a large proportion of studies have targeted famous world heritage destinations, such as the Great Zimbabwe World Heritage Site [21], the Lenggong Valley in Malaysia [22], and the Wuyishan Scenery District in China [23]; however, small cities and heritage destinations not on UNESCO's list have not garnered sufficient attention from academia. As one of the typical examples of such commodified heritage destinations, we empirically examined Sanfang Qixiang so that it can serve as a benchmark for future research on similar cases worldwide.

Third, being "multi-sold" and "multi-consumed" [24] (p. 23), many heritage destinations are shared by both locals and tourists. Despite the importance of the locals, who also act as participants in the tourism activities, previous heritage tourism research has only highlighted the motivations, perceptions, preferences, and satisfactions of the tourists $[25,26]$. As shared users of heritage destinations, locals are often portrayed as service providers and, as such, are usually related to their perspectives and attitudes towards tourism development of heritage in their community [27]. Possessing rich knowledge of local culture, understanding the locals as another user group is necessary for the sustainable operation of tourism activities and to prevent the erosion of heritage and culture. The justification for our dual-focused approach to outside visitors from the tourist gaze perspective and locals consuming the heritage within their daily lives is based on the blurry distinction between normal and tourist lives, which will be discussed in more detail later. 
This study is based on the dyadic function of heritage destinations for both locals and tourists: heritage as a spatial-temporal object for tourists [28] and a place where residential and tourism spaces are integrated and expanded to everyday activities [29]. The purposes of this study were to compare the perceptions of locals and tourists toward authenticity in Sanfang Qixiang and identify the antecedents and consequences of their perceptions of authenticity. Specifically, the study aimed to answer how locals and visitors from outside of Fuzhou perceived authenticity in Sanfang Qixiang as well as what factors influenced their perceptions and how their perceptions were different or similar to each other. The moderating effect of residential status on the relationship between authenticity and destination experience was also investigated.

This study aimed to examine how locals and tourists perceived the authenticity of one particular heritage destination. Specifically, this study set out to examine the (1) effects of cultural motivations and prior knowledge on authenticity, including both object-based and existential authenticities; (2) causal relationship between authenticity and destination experience; and (3) moderating role of residential status on the relationship between authenticity and destination experience. This study tried to fill the research gaps summarized above by investigating the perception of authenticity from dyadic perspectives and providing new Asian content for current authenticity and heritage tourism research, enriching the academic field, which is limited to Western destination cases. Additionally, this study provides information on balanced management strategies that will minimize potential conflicts and maximize user satisfaction, considering both locals and domestic tourists.

\section{Literature Review and Hypotheses Development}

\subsection{Cultural Heritage and Tourism}

Heritage is comprised of the tangible assets of both the natural and cultural environments, while heritage (or cultural heritage) tourism is defined as "traveling to experience the places, artifacts, and activities that authentically represent the stories and people of the past and present" [30]. As part of the broader category of cultural tourism, heritage tourism is a special form of tourism in which tourists experience/consume cultural heritage (e.g., monuments, museums) and cultural experiences (e.g., festivals, communities) [31]. Heritage tourism is more place-based than cultural tourism, creating a sense of place via local landscapes, built environments, and traditions [32].

Heritage tourism can stimulate local economic growth by boosting consumption, creating jobs, and bringing in public funds for conservation and interpretation [33]. It can improve the welfare of the local community through infrastructure construction and by enhancing the awareness of individuals and local governments in regard to the need to protect and conserve local culture and heritage assets [34]. In addition, it can foster place competitiveness, which helps promote local culture and heritage; shape place identity, arousing local people's pride and interests toward their community; retain and preserve cultural values due to the increased demand for tourism; develop a new culture through the relationship between locals and domestic tourists; and add new features and different meanings to existing value [35].

However, the popularity of heritage tourism can also lead to negative consequences. First, the commoditization of heritage becomes commonplace $[34,36]$. The lucrative potential of heritage tourism often blinds tourism managers who focus on revenue instead of long-term interests.

Second, the process of commoditization further leads to a loss of authenticity and the uniqueness of the destinations [37]. Comprehensive debates on the negative impacts of tourism commodification among tourism researchers have shown that it deprives locals and tourists of the real meaning and cultural value of the place; reduces local identity; influences cultural standardization; and can result in cultural conflict [38,39].

Third, increased visitation, over-exploitation, and inappropriate use place heavy burdens on destinations $[36,40]$. Heritage destinations operating over capacity can violate 
sustainable development principles and have detrimental effects on the protection of the sites, particularly on more susceptible heritage assets [15].

The rise of the heritage industry has caused a conflict between heritage protection and tourism development $[34,36]$. It is difficult for heritage destinations to reach the perfect balance as focusing on conservation policies will reduce access to heritage destinations, which will reduce tourism and the funds necessary for conservation. Instead of being shortsighted about the current benefits of tourism development, tourism managers should consider the long-term sustainability of heritage tourism management [41]. This challenge needs to be solved through more theoretical investigations and practical applications. With its vast territory and long history, China is rich in heritage resources [1]. As such, a growing number of domestic tourists are travelling to ancient towns, villages, and historic and cultural streets to experience different cultures at different times, seek their real selves, and escape from their fast-paced lives. In 2015, the Chinese tourism industry earned CNY 3.32 trillion (USD 480 billion), up 10.5\% from 2014, with more than four billion people having traveled to and within China for personal and leisure purposes [42].

\subsection{Authenticity in Tourism Products/Experiences}

According to the field of etymology, authenticity comes from a classical Greco-Roman origin, indicating that something is genuine, true, and sincere [43]. The idea of authenticity is often used in the context of a museum [7] in order to estimate the price or value of an object. Authenticity can only be invoked when tourism products (e.g., works of arts, festive events, rituals, local cuisine, clothing, built environments, natural spaces) are produced, reproduced, or enacted by local people at the tourist destination [44].

MacCannell's [6] study on 'staged authenticity' mentioned that frontstage places are developed for tourists and locals performing services, whereas backstage places are where locals live and act and tourists want to visit. Tourist spaces could be made to appear backstage when frontstage people are just as "dressed up" and "artificial" [6] (p. 599). As such, "contrived tourist spaces" can be manipulated to look like more real than they actually are [45] (p. 264). After MacCannell's [6] introduction of the concept of authenticity into the study of tourism, the subject has become a vital element in heritage tourism and the central attribute of a meaningful experience to ensure sustainable development principles for heritage tourism [46]. Authenticity increases the quality of heritage tourism [47], leading to an increase in the perceived value of and tourists' satisfaction with the tourist destination [48].

Studies have suggested that authenticity in tourism research can be conceptualized with objective, constructive, and existential phenomena [44]. Objective authenticity is related to the property/contents in which toured objects, such as historical buildings or traditional artifacts, are "certified to be authentic without any reason for questioning the authenticity" [43] (p. 51). These physical objects are perceived by tourists as either authentic or inauthentic based on the object's intrinsic quality. Constructive authenticity is a socially constructed concept and determined by the context of where and when the object is situated as well as by whom it is perceived. It depends on individuals' subjective beliefs, opinions, and/or perspectives toward toured objects instead of the objectively inherent quality of the objects [49]. Existential authenticity is an activity-related authenticity, referring to the existential state of being where one can find the true self [50].

Both object-based and constructive authenticity are related to the toured object. The former requires the unquestionable genuine authenticity of the object, which can, thus, ensure authentic tourist experiences, whereas the latter emphasizes the significance of the tourists' interpretations. As long as the tourists perceive the object as real, even if it is actually a reproduction of the past, their tourism experiences will be judged as authentic.

On the other hand, tourists' feelings play a key role in determining activity-related existential authenticity [44]. Regardless of the real or false quality of tourism activities, the tourist will gain authentic experiences if his/her needs and benefits sought are fulfilled (e.g., relaxation, self-enhancement, family togetherness) through the activities. Even though 
tourism research around authenticity has made progress from the objective to the subjective aspects, much research has shown that no objective or constructive authenticity can explain tourists' experiences perfectly by themselves [44].

Past studies on perceptions of authenticity in heritage tourism have focused on the tourists' perceptions, whereas limited studies have focused on locals' perceptions about this issue. As such, this study takes a dual focus, which allows us to study the mutual gazes of tourists to locals, locals to tourists, and among the tourists themselves [11]. Maoz [11] stated that "the local gaze is based on a more complex, two-sided picture, where both the local and tourist gazes exist, affecting and feeding each other, resulting in what is termed 'the mutual gaze'” (p. 222). This mutual gaze helps locals and tourists intersect, and each gaze has a constant effect on the other [11]. As Urry [10] suggested, the concept of a tourist gaze means that tourists have their own expectations of the local people in their pursuit of the authentic experience at heritage tourism sites [51]. As such, it is necessary to integrate the mutual gaze into heritage tourism literature to investigate how both locals and tourists perceive tourism as significant in order to determine how tourism destinations can work toward authenticity and sustainability [52].

\subsection{Cultural Motivation and Authenticity}

Motivation is an important variable by which to understand tourist behaviors. It has been referred to as psychological or physical needs aroused by a state of disequilibrium that might be satisfied through certain behaviors or activities $[53,54]$. Cultural motivation refers to "a set of cultural motives, which are shifting toward a more general interest in culture, rather than very specific cultural goals" [55] (p. 655) and is one of the basic types of travel motivations [56]. Tourists visiting a heritage destination can have either high or low cultural motives, depending on their behaviors, and are motivated by cultural elements, such as participating in festivals, appreciating traditional architecture, and experiencing local cultures $[33,47]$.

Cultural motivation (e.g., a collection of interests in culture(s), history, and heritage) involves tourists who have high cultural motives as well as less culturally engaged tourists [57]. The use of cultural motivation enables the identification of heritage tourists with high cultural motives from general tourists who visit Sanfang Qixiang for relaxation and socialization [58]. Previous research on cultural motivation has showed that it can help researchers understand how individuals perceive authenticity during their visits to heritage destinations [55,57]. Additionally, MacCannell [6] connected authenticity with tourism motivation in that tourists seek to have authentic experiences, which they cannot experience in their daily lives. As such, it is a useful tool in heritage tourism research as it helps researchers understand the behaviors of heritage tourists, as well as the relationships between motivation and other key variables, such as authenticity, satisfaction, and destination loyalty.

Cultural motivation can be treated as a group of interrelated, intellectually based interests in culture, history, and heritage [55]. This construct is in line with the ' $4 \mathrm{I}^{\text {' motives }}$ (i.e., intellectual curiosity, inspiration, investigation, involvement) suggested by Middleton and Clarke [59]. Basic motivations related to visitors' motivations to cultural destinations were mental relaxation, having a good time with friends, increasing knowledge, and discovering new places and things [59]. From this standpoint, cultural motivation is found among both serious and less serious cultural tourists [60], seeking either knowledge related to motivation or pertinent to relaxation motivation. Since motivation influences tourists' expectations [61], cultural motivation has a positive influence on both types of authenticity. In other words, if tourists are involved with and knowledgeable about tourism destinations, their perceptions related to the authenticity of the tourism destinations increase [47]. Tourists perceive higher levels of object-based and existential authenticity when they experience cultural tourism, as tourists' cultural motivations are mostly connected to high perceptions of authentic value [62]. 
According to the prior consumer-based model of authenticity [55], cultural motivation was the main factor affecting the object-based and existential authenticity of tourism destinations. In particular, Kolar and Zabkar's [55] study on Romanesque heritage destinations revealed that cultural motivation has a significant impact on both object-based and existential authenticity. Bryce et al. [57] extended the model and confirmed the strong positive influence of cultural motivation on object-based authenticity. Therefore, based on the previous literature, this study proposes that the cultural motivation of locals and domestic tourists will affect their perceptions of authenticity in Sanfang Qixiang. Thus, the following hypotheses are proposed:

H1a: A cultural motivation for knowledge has a positive impact on the perception of objectbased authenticity.

H1b: A cultural motivation for knowledge has a positive impact on the perception of existential authenticity.

H2a: A cultural motivation for relaxation has a positive impact on the perception of objectbased authenticity.

H2b: A cultural motivation for relaxation has a positive impact on the perception of existential authenticity.

\subsection{Prior Knowledge and Authenticity}

A significant factor related to consumers' information search behaviors is prior product knowledge, which is described as specific information about a product held in an individual's memory [63]. Prior knowledge in the tourism context, therefore, can be defined as destination-specific information held in one's memory. The knowledge can be accumulated through previous experiences with the destination; the experiences of others; information from media channels, such as advertisements, newspapers, and television programs; and ongoing information searches [64]. The information is processed and stored in the individual's long-term memory so as to become his/her prior knowledge about the product [65].

The existing literature suggests that prior knowledge is a multi-dimensional concept composed of familiarity and expertise [63]. Familiarity, a subjective-related concept, refers to an awareness of a product (i.e., how much the individual knows or to what extent the individual thinks he/she know the product) and is an indicator of self-confidence.

The second element, expertise, focuses on professional knowledge and skills. It is defined as "the ability to perform product-related tasks successfully" [63] (p. 411). As an individual becomes experienced in travelling, he/she is more familiar with traveling and the quality of his stored information and knowledge improves. Accumulated knowledge is objective expertise mastered by the individual that is used to tackle task-related problems. Expertise can be further evaluated by the tourist's analysis and elaboration abilities [66].

Studies have emphasized the pivotal role that prior knowledge plays in the information search process [67]. According to Lau [68], knowledge plays a role in MacCannell's object authenticity, which is used to help ascertain the degree of authenticity of a toured object. The achievement of a sense of authenticity is related to personal, prior knowledge of local culture [69]. The antecedent role of prior knowledge on authenticity has been investigated by several studies in the tourism field. For instance, in a qualitative study of authenticity in Aboriginal cultural tourism, Hodgson [70] revealed that previous experiences or prior knowledge held by the tourists played a significant role in their perceptions of authenticity. A similar conclusion was shown in the study by Yang and Wall [71] that focused on ethnic tourism. The authors argued that authenticity might be misinterpreted under the impact of tourists' limited knowledge and previous experiences. Therefore, this paper proposes that prior knowledge will impact perceptions of authenticity related to a heritage destination. As a multi-dimensional construct, prior knowledge in this paper will be measured using familiarity and expertise. The following hypotheses are therefore proposed:

H3a: Prior knowledge has a positive impact on the perception of object-based authenticity. 
H3b: Prior knowledge has a positive impact on the perception of existential authenticity.

\subsection{Authenticity and Destination Experiences}

Extended from the business field, tourist experiences first became a popular research topic in the 1970s $[6,8,10,44,71]$. Tourist experiences can be defined as the psychological responses that appear during activities or traveling that aim to satisfy an individual's requirements/needs [20]. Tourist experiences are subjective reflections of tourists' behaviors.

Studies on the tourist experience have developed a postmodern perspective of destination experiences [72]. For example, Uriely [72] analyzed the four stages of the development $[6,71]$ of tourist experience conceptualization. The first stage perceives tourism as a quest for novelty, extraordinariness, and/or authenticity that does not exist in an individual's daily life. The second stage states that the depictions of tourist experiences have been transformed from a general concept to diverse types of experiences [71]. The third stage considers the tourist experience to be a diverse phenomenon. Scholars have articulated the importance of an individual's practices and perspectives during their experiences, especially authentic experiences at heritage tourism destinations [44]. The last stage is the movement from contradictory and decisive statements to relative and complementary interpretations of experiential meanings [72].

Similarly, one of the most famous typologies in experience is the experience economy theory presented by Pine and Gilmore [73]. According to the authors, experience falls into four dimensions based on whether the experience includes active or passive participation of an individual and on the absorption or immersion of the individual in the experience: entertainment, educational, esthetic, and escapist [73,74].

Additionally, Cohen [71] proposed five modes of touristic experiences to illustrate the diversity of tourists in postmodern tourism: recreational, diversionary, experiential, experimental, and existential. To examine the role of novelty in tourist experiences, Bello and Etzel [75] compared novelty and commonplace experiences via educational and restful experiences. A review of the related literature suggests that tourist experiences are a relative construct, involving the psychological or subjective reactions of an individual to spatial-temporal stimuli [76].

Obtaining authentic experiences is the ultimate goal of heritage tourism and long pursued by both tourism managers and tourists [77]. As an important factor influencing the destination experience, the relationship between authenticity and the destination experience is worth noticing. Prior studies found that the concept of perceived authenticity has been regarded as a consequence/output of tourist experience with a certain place [55]. Meanwhile, a handful of researchers on this topic posit the authenticity as an important antecedent of outcome variables, such as destination experiences, satisfaction, and revisit intention [78-81]. For instance, Grayson and Martinec [78] and Poria, Butler, and Airey [80] suggest perceived authenticity is often considered as an important driver, value, motive, or interest of tourists.

In the heritage tourism context, the concept of authenticity provides the foundation for successful consumption of cultural offerings [81]. The consequence role of the tourist destination experience was also confirmed in Ramkissoon and Uysal's [82] study, which demonstrated that tourists' perceived authenticity has a positive impact on their behavioral intentions toward cultural tourism consumption. In the field of food tourism, prior research proposes that the tourists' degree of pursuit for authenticity influences gastronomic and cultural experiences at a destination [83,84]. In addition, Gupta and Sajnani $[85,86]$ found that food authenticity is an important factor for the overall destination experiences. Hence, the following hypotheses arise:

H4: The perception of object-based authenticity has a positive impact on the destination experience.

H5: The perception of existential authenticity has a positive impact on the destination experience. 


\subsection{Moderating Role of Residential Status}

Whereas authenticity has been considered a significant factor in destination experience, researchers have not systematically investigated how locals and tourists perceive authenticity differently and how that may be a moderating factor in heritage tourism. Considering the fundamental function that residential status holds in authenticity, an examination of residential status as a moderating factor can make a significant contribution to the understanding of the concept.

Chhabra et al. [47] mentioned the importance of authenticity for managing cultural heritage destinations and highlighted the significance of carefully examining this concept in depth. With only limited prior knowledge and experience, at times, visitors can perceive a high degree of authenticity toward the object within the destination experience; it is observed that, even when the visitors are from heterogeneous cultural traditions, a high perception of authenticity may still transpire [47]. As stated by Wang [44], it is widely known that locals tend to stress a constructive authenticity on the basis of cultural norms, especially as they are related to the languages and traditions inherited and shared within their own societies. As MacCannell [28] stated, the authenticity that is experienced when pseudo-events or staged authenticity occurs causes tourists' perceptions of authenticity to be no more than epistemological experiences of toured objects that have been found to be authentic. The label of authenticity of a host culture and tradition can be attached to visited cultures based on (or according to) the stereotyped images and expectations held by the members of the tourist-sending society. Thus, tourists' experiences may exist in the blurry areas between the copy and the original and sign and reality, with no distinction between the real and the fake [87]. This phenomenon is also germane to objective authenticity, which is a similar view of staged authenticity as found in Duncan [88].

On the other hand, tourists are more likely to emphasize an existential authenticity that focuses on feelings, sensations, relationships, and a sense of self, which are associated with the pleasure and enjoyment of the cultural and leisure elements of cultural tourism [41,44]. Interestingly, Mura and Lovelock [12] concluded that locals perceive a lower level of authenticity from their destination experiences than the authenticity experienced by outside visitors and tourists.

Overall, authenticity plays a significant role in perceived authenticity and destination experiences and, as such, needs to be taken into consideration when studying heritage tourism sites. To fill this research gap in the literature, this research utilizes residential status (i.e., locals vs. tourists) as a moderating construct between authenticity and destination experience. Thus, the following hypotheses are proposed:

H4a: The relationship between object-based authenticity and destination experience may differ depending on residential status.

H5a: The relationship between existential authenticity destination and destination experience may differ depending on the residential status.

\subsection{Proposed Model}

The study context of the current research is Sanfang Qixiang, where traditional architecture and the city system coexist with modern development. During its restoration, Sanfang Qixiang was the topic of intensive discussions among locals [19,89]. Since 2005 and continuing throughout the duration of the Chinese government's reformation project, the Chinese government has claimed that they followed the principle of restoration as in the past; however, many old houses were torn down with the government claiming that they were too old and narrow [89]. They were replaced by pseudo-classic houses, which eventually led to loss of the original authenticity of Sanfang Qixiang. Instead, the locale now offers staged authenticity for its visitors [47].

Second, Sanfang Qixiang solved the problem of its high population density at the expense of its vitality. Continually allowing people to move into Sanfang Qixiang led to crowding and poor living conditions. In order to improve the situation, the government 
decided to remove the locals. The new Sanfang Qixiang is now criticized by the local residents as an empty nest, discarding the unique flavor of daily life in Fuzhou.

Third, the modernization and commoditization caused the issue of "sameness" and deprived the locals and tourists of the uniqueness of Sanfang Qixiang [90,91]. This modernization and commoditization came to a peak when several modern chain stores were introduced to the area a few years ago. Locals argued that these brands, such as McDonald's, Watsons, and Starbucks, ruined the destination's uniqueness and caused it to look like a Westernized form of the original [92]. Previous studies have reported that a large portion of Sanfang Qixiang's visitors consider it neither special nor different from other historic/cultural streets in China [81,90].

Ironically, the commoditization of Sanfang Qixiang upset the locals but has created demand for staged experiences and attracted an increasing number of tourists each year, making it one of the most famous destinations in Fuzhou. As such, one must ask: Why has this place, which has faced strong criticism in the past, become a popular destination among locals and tourists? How do these two user groups perceive Sanfang Qixiang? What are the factors causing these perceptions and what are the results they will bring to locals and tourists' destination experiences? To answer these questions, this study conducted a comparative analysis to explore the similarities and differences between the locals and tourists by examining the effects of perceived authenticity on their destination experiences (see Figure 1).



Figure 1. Proposed conceptual model.

\section{Method}

\subsection{Study Site}

Fuzhou, the capital city of the Fujian Province, is a foreign trade port along the southeast coast of China. More than 2000 years old, Fuzhou has plentiful historic and cultural assets. As a landmark of Fuzhou, Sanfang Qixiang is one of the area's most famous scenic spots. Located in the city center of Fuzhou, Sanfang Qixiang covers an area of 40 hectares and contains over 200 ancient houses. Originally built in the late Western Jin Dynasty (265-316), it is composed of the main South Backstreet, three lanes, and seven alleys.

Sanfang Qixiang preserved the basic street patterns of the Tang and Song dynasties (618-1279). In addition, it has 159 buildings in the Ming and Qing dynasties' (1368-1911) styles. Sanfang Qixiang is the only remaining lane and alley system in a Chinese urban area and, as such, is regarded as the "living fossil of the ancient city street system" [93]. The slate grey tiled roofs and ivory walls of the ancient architecture embody the quintessence of traditional Min-Yue dwellings Figure 2. The South Backstreet lantern market and other 
stores reflect the original life of the Fuzhou people. The waterside pavilion inside Yijin Lane, a timber-structure containing a monolayer terrace supported by four pillars, is an ancient performing stage of aesthetic value and perfect acoustics used for the Fuzhou opera Figure 3.

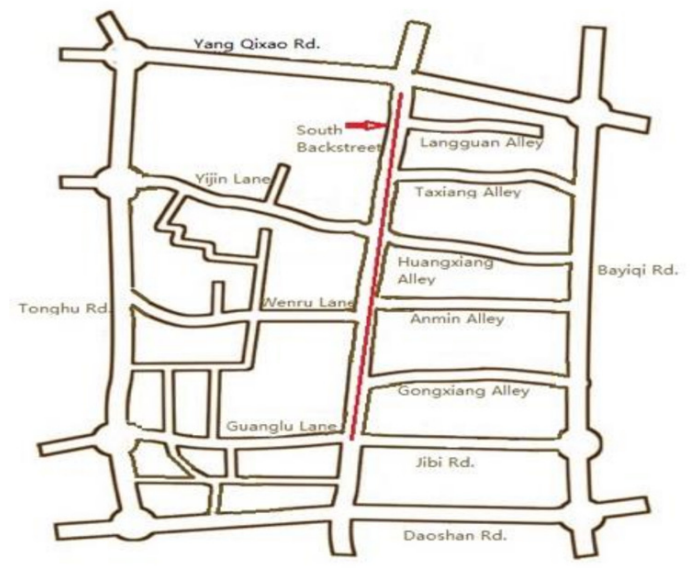

Figure 2. The map of Sanfang Qixiang [92].

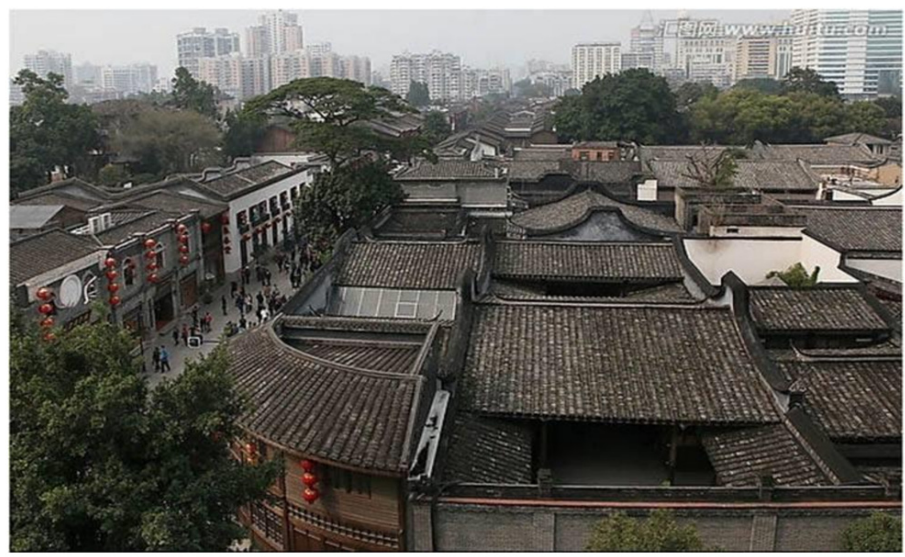

Figure 3. Architecture style in Sanfang Qixiang [92].

Due to transportation developments and daily life necessities, Guanglu Lane, Yangqiao Alley, and Jibi Alley were broadened into main roads by the local government. After the Republic of China era (1912-1949), only two lanes and five alleys remained. Since that point, Sanfang Qixiang has gone through different degrees of damage, either by fires or population movements. In 1993, the Fuzhou government tried to develop the Sanfang Qixiang area. However, the contract was halted, and in 2005, the government put on the agenda the restoration and protection of Sanfang Qixiang as a historic and cultural area. The area was opened to locals and visitors as a tourist attraction and was ranked first on the "Top 10 Historic and Cultural Streets of China" by the Ministry of Culture and the State Administration of Cultural Relics. It was added to the UNESCO World Heritage Tentative List in 2013 and then designated a National Historic and Cultural Street by the Ministry of Housing and Urban-Rural Development in 2015. With the increase in its number of annual visitors, in 2016, it received 10.9 million visitors [3].

\subsection{Sampling and Data Collection}

The samples for this study were Fuzhou locals and domestic tourists visiting Sanfang Qixiang during the research period. Based on the information presented by Su and Wall [94], the individuals in this study were considered locals if they had been living in Fuzhou for at least one year, and tourists referred to individuals who came from other cities in 
China to visit Sanfang Qixiang mainly for leisure purposes. An on-site, self-administered questionnaire was conducted in Sanfang Qixiang from 10 April 2017 to 2 May 2017. A convenience sampling method was used. In total, 400 questionnaires were distributed (i.e., 200 for locals and 200 for tourists). The questionnaires were delivered by five trained college students in popular areas inside Sanfang Qixiang, such as coffee shops, museums, and tourist spots. When approaching the potential participants, field surveyors with proper training for the survey first explained their purpose to make sure that the individuals were willing to participate. After the respondents finished the questionnaires, they were thanked with a small local souvenir, such as a key chain or postcard. A total of 383 questionnaires (i.e., 200 locals and 183 tourists) were received (i.e., response rate of 95.7\%). After 51 invalid questionnaires were removed, a total of 332 usable questionnaires were obtained (i.e., 173 locals and 159 tourists) for the data analysis.

\subsection{Data Analysis}

Structural equation modelling (SEM) was the statistical approach used in this study because it is considered to be one of the most appropriate research methods to show hypothetical relationships among research constructs [95]. This study employed Anderson and Gerbing's [96] two-stage procedure, which identifies the most suitable measurement model in the first stage before estimating the structural model in the second stage. The two-stage procedure is superior to a one-stage procedure in terms of testing theories and evaluating convergent and discriminant validity for survey items [96]. First, a confirmatory factor analysis (CFA) was employed to determine the most suitable measurement model among the survey items. Second, the hypothetical relationships among the constructs, as the second stage, were tested in the structural model [97]. In the third stage, multiple-group analysis was performed to examine the moderating roles of residential status. The data were analyzed using SPSS version 26.0 and Amos version 27.0.

\subsection{Measurements of the Variables and Survey Composition}

The questionnaire for this study contained two sections. In section one, the respondents were asked about their visiting motivations, prior knowledge about Sanfang Qixiang, perceptions of authenticity, and destination experiences. Five subjects were included: cultural motivation for relaxation, motivation for knowledge, object-based authenticity, existential authenticity, and destination experience. In section two, the respondents were asked about their past experiences both in Sanfang Qixiang and other Chinese heritage destinations. They were also asked about their demographic information, such as gender, age, education, occupation, and personal monthly income. The original questionnaire was designed in English and then translated into Chinese.

This study adapted Wang's [44] typology of authenticity in the context of a cultural heritage site. The object-based component was defined as the respondents' perceptions of the historical buildings, architecture, and traditional physical artifacts [98]. However, guided by previous studies [44,55], this study did not directly examine object-based authenticity (i.e., how original artifacts are). Instead, it examined authenticity in a constructive sense (i.e., how inspiring artifacts are). The existential authenticity component was associated with the feelings and emotions of the individuals (i.e., how emotionally they felt connected with the related history, legends, and historical personalities). In particular, the 'getting closer to history' component was crucially important in regard to experiencing the authenticity of heritage sites $[38,47,55]$. The measurement items were developed by reflecting on Sanfang Qixiang's cultural and historical context (Table 1).

A 5-point Likert scale was used, with anchors from strongly disagree (1) to strongly agree (5). The first three variables were examined using scales of cultural motivation, prior knowledge, and authenticity. The questions on cultural motivation (motivation for relaxation and motivation for knowledge) were adapted from Kolar and Zabkar [55]. The questions on prior knowledge were based on the information presented by Kerstetter and Cho [99]. The questions on authenticity (object-based authenticity and existential authentic- 
ity) were reflective of the items presented by Kolar and Zabkar [55]. The destination experience questions were derived from Zhang and Seo [86]. Including the socio-demographic questions, the questionnaire contained 33 items.

Table 1. Measurements of variables.

\begin{tabular}{|c|c|c|c|}
\hline & ibles & Measurements & Source \\
\hline \multirow{6}{*}{$\begin{array}{l}\text { Cultural } \\
\text { Motivation }\end{array}$} & \multirow{3}{*}{$\begin{array}{l}\text { Motivation for } \\
\text { Relaxation }\end{array}$} & Relax mentally & \multirow{6}{*}{$\begin{array}{l}\text { Kolar and } \\
\text { Zabkar [55] }\end{array}$} \\
\hline & & Discover new places and things & \\
\hline & & Be in a calm atmosphere & \\
\hline & \multirow{3}{*}{$\begin{array}{l}\text { Motivation for } \\
\text { Knowledge }\end{array}$} & Visit cultural attractions/events & \\
\hline & & Visit historical attractions/events & \\
\hline & & Interest in history & \\
\hline \multirow{4}{*}{\multicolumn{2}{|c|}{ Prior Knowledge }} & $\begin{array}{l}\text { Compared to the average person, I am very familiar with where I have been } \\
\text { in Sanfang Qixiang }\end{array}$ & \multirow{4}{*}{$\begin{array}{l}\text { Kerstetter and } \\
\quad \text { Cho [99] }\end{array}$} \\
\hline & & $\begin{array}{l}\text { Prior to visiting Sanfang Qixiang, I was familiar with the customs and } \\
\text { traditions of Fuzhou }\end{array}$ & \\
\hline & & $\begin{array}{l}\text { Compared to people who travel a lot, I am very familiar with where I have } \\
\text { been in Sanfang Qixiang }\end{array}$ & \\
\hline & & $\begin{array}{l}\text { Compared to my friends, I am very familiar with where I have been in } \\
\text { Sanfang Qixiang }\end{array}$ & \\
\hline \multirow{8}{*}{ Authenticity } & & Traditional lifestyle and culture can be acknowledged in Sanfang Qixiang & \multirow{8}{*}{$\begin{array}{l}\text { Kolar and } \\
\text { Zabkar [55] }\end{array}$} \\
\hline & & Sanfang Qixiang is preserved the way it was back in the time & \\
\hline & $\begin{array}{l}\text { Object-based } \\
\text { Authenticity }\end{array}$ & $\begin{array}{l}\text { The exhibits in Sanfang Qixiang are real products from the Ming and } \\
\text { Qing Dynasties }\end{array}$ & \\
\hline & & The buildings in Sanfang Qixiang are built in traditional ways & \\
\hline & \multirow{4}{*}{$\begin{array}{l}\text { Existential } \\
\text { Authenticity }\end{array}$} & $\begin{array}{l}\text { I liked the special arrangements, events, concerts, and celebrations } \\
\text { connected to the site }\end{array}$ & \\
\hline & & This visit provided a thorough insight into Sanfang Qixiang's historical era & \\
\hline & & $\begin{array}{l}\text { During the visit, I felt connected with the related history, legends, and } \\
\text { historical personalities }\end{array}$ & \\
\hline & & I liked the calm and peaceful atmosphere during the visit & \\
\hline \multirow{4}{*}{\multicolumn{2}{|c|}{ Destination Experience }} & The experience of visiting Sanfang Qixiang is interesting & \multirow{4}{*}{$\begin{array}{c}\text { Zhang and Seo } \\
{[86]}\end{array}$} \\
\hline & & The experience of visiting Sanfang Qixiang makes me more knowledgeable & \\
\hline & & The experience of visiting Sanfang Qixiang is pleasant & \\
\hline & & $\begin{array}{c}\text { The experience of visiting Sanfang Qixiang is attractive, with many places } \\
\text { worth a visit }\end{array}$ & \\
\hline
\end{tabular}

\section{Results}

\subsection{Characteristics of the Respondents}

The socio-demographic characteristics of the Fuzhou locals and domestic tourists are presented in Table 2. Of the 173 Fuzhou locals, $43.4 \%$ were male, $56.6 \%$ were female, and $55.5 \%$ were aged below 29. In addition, $69.6 \%$ had been to Sanfang Qixiang more than five times. In total, $97.4 \%$ of the local respondents were repeat visitors. For their past experiences at other Chinese heritage sites, $43.5 \%$ had visited more than three places. The locals tended to be educated with relatively high income and experienced heritage tourists. 
Table 2. Socio-demographic characteristics of locals and tourists.

\begin{tabular}{|c|c|c|c|}
\hline & \multirow{2}{*}{ Variables } & \multirow{2}{*}{$\begin{array}{c}\text { Fuzhou Locals }(N=173) \\
\text { Frequency }(\%)\end{array}$} & \multirow{2}{*}{$\begin{array}{c}\text { Domestic Tourists }(N=159) \\
\text { Frequency }(\%)\end{array}$} \\
\hline & & & \\
\hline \multirow{2}{*}{ Gender } & Male & $75(43.4)$ & $55(34.6)$ \\
\hline & Female & $98(56.6)$ & $104(65.4)$ \\
\hline \multirow{6}{*}{ Age } & Below 19 & $20(11.6)$ & $9(5.7)$ \\
\hline & $20-29$ & $76(43.9)$ & $81(50.9)$ \\
\hline & $30-39$ & $27(15.6)$ & $36(22.6)$ \\
\hline & $40-49$ & $25(14.5)$ & $22(13.8)$ \\
\hline & $50-59$ & $23(13.3)$ & $8(5.0)$ \\
\hline & Above 60 & $2(1.2)$ & $3(1.9)$ \\
\hline \multirow{3}{*}{ Education } & High school and below & $57(32.9)$ & $40(25.2)$ \\
\hline & Undergraduate & $97(56.1)$ & $87(54.7)$ \\
\hline & Graduate & $19(11.0)$ & $32(20.1)$ \\
\hline \multirow{9}{*}{ Occupation } & Student & $49(28.3)$ & $41(25.8)$ \\
\hline & White collar & $49(28.3)$ & $49(30.8)$ \\
\hline & Professional & $21(12.1)$ & $17(10.7)$ \\
\hline & Government Officer & $12(6.9)$ & $8(5.0)$ \\
\hline & Freelancers & $17(9.8)$ & $16(10.1)$ \\
\hline & Self-employed & $8(4.6)$ & $8(5.0)$ \\
\hline & Housewife & $1(0.6)$ & $10(6.3)$ \\
\hline & Retired & $6(3.5)$ & $5(3.1)$ \\
\hline & Others & $10(5.8)$ & $5(3.1)$ \\
\hline \multirow{4}{*}{ Income $^{1}$} & Below $2000 \mathrm{CNY}$ & $53(30.6)$ & $48(30.2)$ \\
\hline & 2000-3999 CNY & $43(24.9)$ & $47(29.6)$ \\
\hline & 4000-5999 CNY & $36(20.8)$ & $33(20.8)$ \\
\hline & Above $6000 \mathrm{CNY}$ & $41(23.7)$ & $31(19.5)$ \\
\hline
\end{tabular}

${ }^{1}$ USD 1 is equivalent to CNY 6.5.

In the sample of the 159 tourists, $34.6 \%$ were male and $65.4 \%$ were female. Similar to the local respondents, $56.6 \%$ of the tourists were aged 29 or younger. The average income of the tourists was lower than that of the locals. The tourists had higher education levels than the locals and less experience in heritage tourism.

\subsection{Confirmation Factor Analysis}

A confirmation factor analysis (CFA) was conducted to examine the unidimensionality of the scales and validate the measurement model. The results showed that the model fit of the measurement model was satisfactory $(\mathrm{CMIN}=404.118 ; \mathrm{df}=189 ; \mathrm{CMIN} / \mathrm{DF}=2.138$; $p<0.001 ; \mathrm{GFI}=0.905 ; \mathrm{CFI}=0.940 ; \mathrm{NFI}=0.894 ; \mathrm{IFI}=0.941 ; \mathrm{RMSEA}=0.059 ; \mathrm{RMR}=0.042$ ).

In addition, in order to explore the adequacy of the variables that measured the construct validity of the measurement model, convergent and discriminant validity were examined. As shown in Table 3, the factor loading value was from 0.600 to 0.891 , which exceeded the standard value of $\geq 0.5$. The composite reliability (CR) was also statistically significant, and the construct reliability was from 0.781 to 0.884 (standard value: $\geq 0.7$ ). The average variance extracted (AVE) for all of constructs was 0.504 to 0.725 , except for existential authenticity (0.487), which was higher than the threshold value of $\geq 0.50$ [100]. If the AVE is below than 0.5 , having CR values greater than 0.6 is still adequate [100]. As such, 
the results indicated the satisfactory level of the internal consistency [101]. Finally, discriminant validity was secured when the AVE for each construct was larger than its squared correlation for each pair of constructs. Overall, the results demonstrated satisfactory convergent validity, internal consistency, and discriminant validity for the measurement scales. The results of discriminant reliability and validity test were presented in Table 4.

Table 3. CFA and model fit on the measurement model.

\begin{tabular}{|c|c|c|c|c|c|c|c|c|c|}
\hline \multirow{3}{*}{ Construct and Scale Items } & \multicolumn{3}{|c|}{ CFA } & \multicolumn{6}{|c|}{ MCFA } \\
\hline & \multirow{2}{*}{$\begin{array}{l}\text { Factor } \\
\text { Loading }\end{array}$} & \multirow[b]{2}{*}{$t$-Value } & \multirow[b]{2}{*}{$\begin{array}{l}\text { C.R. } \\
\text { (AVE) }\end{array}$} & \multicolumn{3}{|c|}{ Locals } & \multicolumn{3}{|c|}{ Tourists } \\
\hline & & & & $\begin{array}{c}\text { Factor } \\
\text { Loading }\end{array}$ & $t$-Value & $\begin{array}{c}\mathrm{CR} \\
\text { (AVE) }\end{array}$ & $\begin{array}{c}\text { Factor } \\
\text { Loading }\end{array}$ & $t$-Value & $\begin{array}{c}\text { CR } \\
\text { (AVE) }\end{array}$ \\
\hline \multicolumn{10}{|l|}{ Motivation for Relaxation (MR) } \\
\hline Relax mentally & 0.651 & $\mathrm{~N} / \mathrm{A}$ & \multirow{3}{*}{$\begin{array}{c}0.781 \\
(0.545)\end{array}$} & 0.635 & $\mathrm{~N} / \mathrm{A}$ & \multirow{3}{*}{$\begin{array}{c}0.752 \\
(0.505)\end{array}$} & 0.665 & $\mathrm{~N} / \mathrm{A}$ & \multirow{3}{*}{$\begin{array}{c}0.810 \\
(0.587)\end{array}$} \\
\hline Discover new places and things & 0.755 & 9.4 & & 0.764 & 6.898 & & 0.711 & 6.098 & \\
\hline Be in a calm atmosphere & 0.600 & 8.408 & & 0.597 & 6.072 & & 0.609 & 5.691 & \\
\hline \multicolumn{10}{|c|}{ Motivation for Knowledge (MR) } \\
\hline Visit cultural attractions/events & 0.845 & $\mathrm{~N} / \mathrm{A}$ & \multirow{3}{*}{$\begin{array}{c}0.854 \\
(0.665)\end{array}$} & 0.867 & $\mathrm{~N} / \mathrm{A}$ & \multirow{3}{*}{$\begin{array}{c}0.840 \\
(0.642)\end{array}$} & 0.782 & $\mathrm{~N} / \mathrm{A}$ & \multirow{3}{*}{$\begin{array}{c}0.874 \\
(0.701)\end{array}$} \\
\hline Visit historical attractions/events & 0.816 & 14.36 & & 0.842 & 11.84 & & 0.813 & 8.573 & \\
\hline Interest in history & 0.605 & 10.827 & & 0.587 & 7.895 & & 0.643 & 7.403 & \\
\hline \multicolumn{10}{|l|}{ Prior Knowledge (PK) } \\
\hline $\begin{array}{l}\text { Compared to the average person, I am very familiar } \\
\text { with where I have been in Sanfang Qixiang }\end{array}$ & 0.727 & $\mathrm{~N} / \mathrm{A}$ & \multirow{4}{*}{$\begin{array}{c}0.884 \\
(0.660)\end{array}$} & 0.756 & $\mathrm{~N} / \mathrm{A}$ & \multirow{4}{*}{$\begin{array}{c}0.897 \\
(0.688)\end{array}$} & 0.636 & $\mathrm{~N} / \mathrm{A}$ & \multirow{4}{*}{$\begin{array}{c}0.884 \\
(0.663)\end{array}$} \\
\hline $\begin{array}{l}\text { Prior to visiting Sanfang Qixiang, I was familiar } \\
\text { with the customs and traditions of Fuzhou }\end{array}$ & 0.658 & 16.541 & & 0.646 & 9.855 & & 0.594 & 10.703 & \\
\hline $\begin{array}{l}\text { Compared to people who travel a lot, I am very } \\
\text { familiar with where I have been in Sanfang Qixiang }\end{array}$ & 0.876 & 14.918 & & 0.872 & 11.517 & & 0.833 & 8.31 & \\
\hline $\begin{array}{l}\text { Compared to my friends, I am very familiar with } \\
\text { where I have been in Sanfang Qixiang }\end{array}$ & 0.891 & 14.972 & & 0.896 & 11.683 & & 0.911 & 8.238 & \\
\hline \multicolumn{10}{|l|}{ Object-based Authenticity $(\mathrm{OA})$} \\
\hline $\begin{array}{l}\text { Traditional lifestyle and culture can be } \\
\text { acknowledged in Sanfang Qixiang }\end{array}$ & 0.713 & $\mathrm{~N} / \mathrm{A}$ & \multirow{4}{*}{$\begin{array}{l}0.802 \\
(0.504)\end{array}$} & 0.72 & $\mathrm{~N} / \mathrm{A}$ & \multirow{4}{*}{$\begin{array}{c}0.819 \\
(0.532)\end{array}$} & 0.65 & $\mathrm{~N} / \mathrm{A}$ & \multirow{4}{*}{$\begin{array}{c}0.791 \\
(0.487)\end{array}$} \\
\hline $\begin{array}{l}\text { Sanfang Qixiang is preserved the way it was back } \\
\text { in history }\end{array}$ & 0.708 & 10.8 & & 0.764 & 9.114 & & 0.601 & 5.552 & \\
\hline $\begin{array}{l}\text { The exhibits in Sanfang Qixiang are real products } \\
\text { from Ming and Qing Dynasties }\end{array}$ & 0.623 & 9.73 & & 0.652 & 7.855 & & 0.637 & 5.746 & \\
\hline $\begin{array}{c}\text { The buildings in Sanfang Qixiang are built in } \\
\text { traditional ways }\end{array}$ & 0.629 & 9.801 & & 0.671 & 8.079 & & 0.631 & 5.719 & \\
\hline \multicolumn{10}{|l|}{ Existential Authenticity (EA) } \\
\hline $\begin{array}{l}\text { I liked special arrangements, events, concerts, and } \\
\text { celebrations connected to the site }\end{array}$ & 0.629 & $\mathrm{~N} / \mathrm{A}$ & \multirow{4}{*}{$\begin{array}{c}0.872 \\
(0.633)\end{array}$} & 0.697 & $\mathrm{~N} / \mathrm{A}$ & \multirow{4}{*}{$\begin{array}{c}0.871 \\
(0.630)\end{array}$} & 0.408 & $\mathrm{~N} / \mathrm{A}$ & \multirow{4}{*}{$\begin{array}{c}0.854 \\
(0.605)\end{array}$} \\
\hline $\begin{array}{l}\text { This visit provided a thorough insight into the } \\
\text { Sanfang Qixiang's historical era }\end{array}$ & 0.851 & 12.001 & & 0.879 & 10.492 & & 0.761 & 4.606 & \\
\hline $\begin{array}{l}\text { During the visit I felt connected with the related } \\
\text { history, legends, and historical personalities }\end{array}$ & 0.699 & 10.494 & & 0.722 & 8.808 & & 0.629 & 4.357 & \\
\hline $\begin{array}{l}\text { I liked the calm and peaceful atmosphere during } \\
\text { the visit }\end{array}$ & 0.661 & 10.132 & & 0.686 & 8.501 & & 0.647 & 4.414 & \\
\hline Destination Experience (DE) & & & & & & & & & \\
\hline $\begin{array}{c}\text { The experience of visiting Sanfang Qixiang } \\
\text { is interesting }\end{array}$ & 0.766 & N/A & & 0.805 & $\mathrm{~N} / \mathrm{A}$ & & 0.71 & $\mathrm{~N} / \mathrm{A}$ & \\
\hline $\begin{array}{l}\text { The experience of visiting Sanfang Qixiang makes } \\
\text { me more knowledgeable }\end{array}$ & 0.782 & 17.728 & 0.913 & 0.781 & 15.135 & 0.910 & 0.779 & 9.196 & 0.913 \\
\hline $\begin{array}{c}\text { The experience of visiting Sanfang Qixiang } \\
\text { is pleasant }\end{array}$ & 0.816 & 14.769 & $(0.725)$ & 0.818 & 12.032 & $(0.717)$ & 0.755 & 7.782 & $(0.724)$ \\
\hline $\begin{array}{l}\text { The experience of visiting Sanfang Qixiang is } \\
\text { attractive, with many places worth a visit }\end{array}$ & 0.747 & 13.488 & & 0.784 & 11.408 & & 0.662 & 7.082 & \\
\hline CFA & $x^{2} / d$ & $404.118 /$ & $2.138, p$ & $\begin{array}{l}.001, \text { GFI } \\
\text { RMSEA }\end{array}$ & $\begin{array}{l}905, \mathrm{CFI}= \\
.059, \mathrm{RMR}\end{array}$ & $\begin{array}{l}940, \mathrm{NFI} \\
0.042\end{array}$ & $894, \mathrm{TLI}=$ & $6, \mathrm{IFI}=0$ & \\
\hline MCFA & $x^{2} /$ & $(672.070 /$ & $1.778, p$ & $\begin{array}{r}\text { 0.001, GFI } \\
\text { RMSEA }\end{array}$ & $\begin{array}{l}853, \mathrm{CFI}= \\
.049, \mathrm{RMR}\end{array}$ & $\begin{array}{l}916, \mathrm{NF} \\
0.045\end{array}$ & $830, \mathrm{TLI}=$ & 7 , IFI $=0$ & \\
\hline
\end{tabular}


Table 4. Discriminant reliability and validity analysis of the measurement model.

\begin{tabular}{ccccccccc}
\hline & \multicolumn{2}{c}{ OA } & \multicolumn{2}{c}{ EA } & \multicolumn{2}{c}{ MR } & \multicolumn{2}{c}{ MK } \\
\cline { 2 - 9 } & $\Phi$ & S.E. & $\Phi$ & S.E. & $\Phi$ & S.E. & $\Phi$ & S.E. \\
\hline EA & 0.698 & 0.03 & & & & & & \\
\hline$\Phi-(2 \times$ S.E $) \sim+(2 \times$ S.E $)$ & 0.638 & 0.758 & & & & & & \\
\hline MR & 0.544 & 0.033 & 0.558 & 0.024 & & & & \\
\hline$\Phi-(2 \times$ S.E $) \sim \Phi+(2 \times$ S.E $)$ & 0.478 & 0.61 & 0.51 & 0.606 & & & & \\
\hline MK & 0.202 & 0.031 & 0.61 & 0.027 & 0.582 & 0.029 & & \\
\hline$\Phi-(2 \times$ S.E $) \sim \Phi+(2 \times$ S.E $)$ & 0.14 & 0.264 & 0.556 & 0.664 & 0.524 & 0.64 & & \\
\hline PK & 0.202 & 0.031 & 0.197 & 0.023 & 0.087 & 0.025 & 0.099 & 0.029 \\
\hline$\Phi-(2 \times$ S.E $) \sim \Phi+(2 \times$ S.E $)$ & 0.14 & 0.264 & 0.151 & 0.243 & 0.037 & 0.137 & 0.041 & 0.157 \\
\hline DE & 0.655 & 0.031 & 0.891 & 0.03 & 0.581 & 0.026 & 0.565 & 0.028 \\
\hline$\Phi-(2 \times$ S.E $) \sim \Phi+(2 \times$ S.E $)$ & 0.593 & 0.717 & 0.831 & 0.951 & 0.529 & 0.633 & 0.509 & 0.621 \\
\hline
\end{tabular}

The discriminant validity of the entire measurement model was calculated using the resulting value of the correlation coefficient between two variables (Estimate, $\Phi$ ) multiplied by \pm 2 times the standard error (SE) between the two variables. The result was not 1 . If the result is not 1 , then discriminant validity is reflected [102].

\subsection{Structural Model and Hypothesis Testing}

The analysis results of the SEM are shown in Table 5 and Figure 4 . The model fit of the structural model was $\mathrm{CMIN}=409.175 ; \mathrm{df}=192 ; \mathrm{CMIN} / \mathrm{DF}=2.131 ; p<0.001 ; \mathrm{GFI}=0.904 ;$ $\mathrm{CFI}=0.942 ; \mathrm{NFI}=0.893 ; \mathrm{TLI}=0.927 ; \mathrm{IFI}=0.940 ; \mathrm{RMSEA}=0.058 ;$ and $\mathrm{RMR}=0.042$, indicating that the research model was suitable. Figure 4 describes the SEM results with standardized coefficients. Most of the hypotheses were statistically supported at $p<0.05$, except $\mathrm{H} 4$ and H4a (see Table 5).

Table 5. Standardized parameter estimates for the structural model.

\begin{tabular}{|c|c|c|c|c|c|c|c|}
\hline $\mathbf{H}$ & \multicolumn{3}{|c|}{ Paths } & Factor Loadings & $t$-Value & $p$-Value & Results \\
\hline H1a & MR & $\rightarrow$ & $\mathrm{OA}$ & 0.305 & 3.391 & $* * *$ & Supported \\
\hline $\mathrm{H} 2 \mathrm{a}$ & MK & $\rightarrow$ & $\mathrm{OA}$ & 0.354 & 4.16 & $* * *$ & Supported \\
\hline H3a & PK & $\rightarrow$ & $\mathrm{OA}$ & 0.142 & 2.415 & $0.016^{*}$ & Supported \\
\hline $\mathrm{H} 1 \mathrm{~b}$ & MR & $\rightarrow$ & EA & 0.33 & 4.04 & $* * *$ & Supported \\
\hline $\mathrm{H} 2 \mathrm{~b}$ & MK & $\rightarrow$ & EA & 0.408 & 5.186 & $* * *$ & Supported \\
\hline $\mathrm{H} 3 \mathrm{~b}$ & PK & $\rightarrow$ & EA & 0.144 & 2.78 & $0.005^{* *}$ & Supported \\
\hline $\mathrm{H} 4$ & $\mathrm{OA}$ & $\rightarrow$ & $\mathrm{DE}$ & 0.068 & 0.895 & 0.371 & Not supported \\
\hline H5 & EA & $\rightarrow$ & $\mathrm{DE}$ & 0.849 & 8.327 & $* * *$ & Supported \\
\hline \multirow{2}{*}{$\mathrm{H} 4 \mathrm{a}$} & \multirow{2}{*}{\multicolumn{2}{|c|}{$\begin{array}{l}\text { Residential status's moderating function between } \\
\text { object-based authenticity and destination experience }\end{array}$}} & Locals & 0.230 & 2.039 & $0.041 *$ & Supported \\
\hline & & & Tourists & -0.112 & -1.086 & 0.277 & Not supported \\
\hline \multirow{2}{*}{ H5a } & \multirow{2}{*}{\multicolumn{2}{|c|}{$\begin{array}{l}\text { Residential status's moderating function between } \\
\text { existential authenticity and destination experience }\end{array}$}} & Locals & 0.765 & 5.883 & $* * *$ & Supported \\
\hline & & & Tourists & 0.819 & 4.090 & $* * *$ & Supported \\
\hline Model fit & \multicolumn{7}{|c|}{$\chi^{2} / \mathrm{df}=(409.175 / 192) 2.131, p<0.001, \mathrm{GFI}=0.904, \mathrm{CFI}=0.942, \mathrm{NFI}=0.893, \mathrm{TLI}=0.927, \mathrm{IFI}=0.940, \mathrm{RMSEA}=0.058, \mathrm{RMR}=0.042$} \\
\hline
\end{tabular}

Notes: ${ }^{*}$ Significant at $p<0.01 ;{ }^{* *}$ Significant at $p<0.01 ;{ }^{* * *}$ Significant at $p<0.001$. 




Figure 4. Standardized theoretical path coefficients. ${ }^{*} p<0.05$; ${ }^{* *} p<0.01$; ${ }^{* *} p<0.001$; S: significant; a path coefficient for locals; ${ }^{b}$ path coefficient for tourists.

\subsection{Moderating Effects of Residential Status}

A multiple-group analysis was conducted to examine the moderating role of residential status on the research model and, thus, further identify the impact of each path for both the groups [103]. First, a factor loading invariance between the groups was employed to check the significance of the chi-square difference between the two CFA models to determine whether the factor loadings were constrained to be equal between groups [104]. As illustrated in Table 6, the chi-square difference between the local and tourist groups was not significant $\left(\Delta \chi^{2}(16)=24.727, p>0.05\right)$, suggesting a factor loading invariance. Thus, a multiple-group SEM was conducted to examine the difference in the path coefficients between the groups, as a valid group comparison can be made "without concern that the differences are due to differing measurement properties between the two groups" [100] (p. 763).

Table 6. Test of the measurement model's group invariance.

\begin{tabular}{|c|c|c|c|c|c|c|c|}
\hline Model & $x^{2}$ & df & $p$-Value & NFI Delta-1 & IFI Delta-2 & RFI rho-1 & Result \\
\hline Measurement weights & 24.727 & 16 & 0.075 & 0.006 & 0.007 & -0.001 & \multirow{3}{*}{$\begin{array}{c}\text { Supported } \\
\Delta \chi^{2}(16)=24.727 \\
p>0.05\end{array}$} \\
\hline Structural covariances & 101.014 & 37 & 0.000 & 0.026 & 0.028 & 0.01 & \\
\hline Measurement residuals & 171.358 & 64 & 0.000 & 0.043 & 0.048 & 0.015 & \\
\hline H4a: $\mathrm{OA} \rightarrow \mathrm{DE}$ & 4.526 & 1 & 0.033 & 0.001 & 0.001 & 0.001 & Supported \\
\hline H5a: $\mathrm{EA} \rightarrow \mathrm{DE}$ & 4.295 & 1 & 0.038 & 0.001 & 0.001 & 0.001 & Supported \\
\hline
\end{tabular}

In the next step, a particular relationship in the constrained model was compared with the unconstrained model to test the moderating effect of residential status on each relationship in the model. Each path in the constrained model was examined in an orderly manner. Table 6 shows that the residential status moderated the relationship between object-based authenticity and destination experience, with significant differences in the chisquare values $\left(\Delta \chi^{2}(1)=4.526, p<0.05\right)$. In addition, existential authenticity and destination experience $\left(\Delta \chi^{2}(1)=4.295, p<0.05\right)$ were significantly different across the two groups (i.e., locals vs. tourists), which suggested that residential status significantly moderated the relationship between authenticity and destination experience.

In order to provide additional insights into these outcomes, this study compared the effect of every structural path across local and tourist groups (Table 7). Figure 4 illustrated 
the moderating effect of residential status on the relationship between authenticity and destination experience in the path model. One distinct difference between the local and tourist groups was that the effect of object-based authenticity on destination experience was significant for the local group ( $\beta$ Locals $=0.23, t=2.039, p=0.041$ ) and insignificant for the tourist group ( $\beta$ Tourists $=-0.112, \mathrm{t}=-1.086, p=0.227$ ). Therefore, H4a was only partially confirmed. However, existential authenticity was a significant precursor of destination experience for both groups, even though the effect of existential authenticity on destination experience was statistically stronger for the tourists ( $\beta$ Tourists $=0.819, \mathrm{t}=4.09$, $p<0.001$ ) than the locals ( $\beta$ Locals $=0.765, \mathrm{t}=5.883, p<0.001$ ), supporting H5a. Thus, it is clear that the locals' destination experiences were significantly moderated by the both object-based and existential authenticity, while the tourists' destination experiences were influenced by existential authenticity.

Table 7. Test results of the multigroup SEMs according to residential status.

\begin{tabular}{|c|c|c|c|c|c|c|c|}
\hline \multirow[b]{2}{*}{ Model } & \multirow[b]{2}{*}{$x^{2}$} & \multicolumn{6}{|c|}{ Contrast with Baseline Model } \\
\hline & & $\mathrm{df}$ & $\chi^{2} / d f$ & $\chi^{2}$ dif & $\mathrm{df}_{\text {dif }}$ & CFI & NFI \\
\hline \multicolumn{8}{|l|}{ Multiple-group CFA } \\
\hline Baseline (no constraints) & $672.071 *$ & 378 & 1.778 & & & 0.916 & 0.830 \\
\hline Factor Loading Invariance & $696.798 *$ & 394 & 1.769 & 24.727 & 16 & 0.913 & 0.823 \\
\hline \multicolumn{8}{|l|}{ Multiple-group SEM Models } \\
\hline Path Invariance & $681.793 *$ & 384 & 1.776 & & & 0.914 & 0.827 \\
\hline H4a: $\mathrm{OA} \rightarrow \mathrm{DE}$ & $686.319 *$ & 385 & 1.783 & 4.526 & 1 & 0.913 & 0.826 \\
\hline H5a: EA $\rightarrow$ DE & 686.087 * & 385 & 1.782 & 4.295 & 1 & 0.913 & 0.826 \\
\hline
\end{tabular}

\section{Discussion and Conclusions}

The purpose of this paper was to investigate the structural relationships among cultural motivation, prior knowledge, authenticity, and the destination experience by conducting multiple-group analysis to test the moderating role of residential status on the relationship between authenticity and destination experience. To reach the research goals, this paper answered several questions.

First, the results showed that cultural motivation had a significant effect on the dimensions of authenticity. Therefore, cultural motivation (i.e., motivation for relaxation and motivation for knowledge) is an important factor in the perception of authenticity in Sanfang Qixiang. It seems that individuals are motivated to visit Sanfang Qixiang for intellectual purposes, such as learning about and exploring cultural and historical attractions/events, and for the sake of relaxing. This result is consistent with recent studies that have shown that cultural motivation was the key determinant for authenticity during both the locals' and tourists' visits to heritage destinations due to the connection between authenticity and cultural motivation [55,57] and because tourists' motivations for knowledge influence their perception of authenticity [47]. The findings of this study support the postmodern approach of the tourist in that tourists seek composite experiences that integrate pleasure and intellectual stimulation [55].

The results also demonstrated the important role of Sanfang Qixiang as a heritage tourism site as well as a commercial area for both locals and tourists. Not everyone goes there for an authentic experience; others can visit Sanfang Qixiang to relax or discover new places and things. In this situation, commoditization in the form of modern coffee shops, restaurants, and a movie theater may be preferred. Therefore, sustainable management strategies are needed to reduce conflicts between the conservation and commoditization of traditional culture. Diverse tourism products and events with cultural aspects can be utilized to entertain people, benefit the community, avoid the phenomenon of "pseudoevents" [8], and preserve the area's unique cultural and traditional heritage. 
In addition, prior knowledge was found to have an important influence on the perception of authenticity. This finding is similar to findings of previous studies [68-70]. The result has practical implications for destination marketing organizations (DMOs) who should enhance authenticity by developing cultural events and historical lessons or lectures about the area. For example, DMOs should make efforts to incorporate existential authenticity with existential tourists (i.e., tourists travelling for a deeper spiritual understanding and connection with the intangible heritage of the place) [105].

To generate connections between stakeholders and the destination for cultural immersion and to reconnect with the local culture, more cultural activities should be encouraged so as to increase the locals' and tourists' participation in local experiences that are generated by and for locals; can be of interest to tourists; and are perceptions of existential authenticity. To educate the locals and tourists on cultural tourism development, tourism managers should collaborate with local schools for educational, leisure, and cultural activities; develop lectures on cultural tourism; and create historical interpretation tours. To interact with locals and tourists, DMOs should organize cultural events that allow people to experience local crafts, such as paper umbrella painting, horn comb making, and paper mounting, and hold various exhibitions and traditional events that present a deeper understanding of Fuzhou. The results of this study were consistent with past studies in the areas of cultural motivation and prior knowledge on the dimensions of authenticity in the context of heritage tourism.

Second, the results showed that existential authenticity helps enhance the destination experience, while object-based authenticity did not significantly influence the destination experience. These results may mean that existential authenticity in Sanfang Qixiang helps enhance the destination experience due to the various cultural events that are regularly held there.

However, the originality of Sanfang Qixiang did not influence peoples' experiences. As stated earlier, limited research with controversial results exists on the relationship between the perception of authenticity and the destination experience [55,78-86]. Unlike past research, the current study incorporated both the locals' and tourists' perspectives, adding to the literature in this area.

Although the mutual effects of these two concepts have revealed the existence of a dynamic relationship between the perception of authenticity and the destination experience, the findings of this study suggest that people are not influenced by object-based authenticity (i.e., knowledge and pleasure in genuine objects, works of art, and architecture in the original site) as they consider the restored Sanfang Qixiang as no longer being authentic. These findings are consistent with prior research that has argued that tourists do not consider Sanfang Qixiang to be special or different from other historic and cultural streets in China [91,92]. Rather, individuals visit Sanfang Qixiang in order to escape from ordinary life and mass tourism; connect with their authentic selves; and feel pleasure and escape [55].

In other words, this study suggests that people may be in search of staged authenticity in tourism destination experiences. Due to the staging of authenticity, people are unable to recognize whether these experiences are original or fake. Turner [106] argued that "the very existence of tourism rules out the possibility of authentic cultural experiences" (p. 185). The findings of this study regarding staged authenticity help us to understand how consumable objects make tourists less uncomfortable when local events are reproduced for them. Marketing strategies should not only emphasize the originality of the tourism products, design of the cultural tourism development experience, and architecture of the cultural heritage destinations, but also produce a sense of uniqueness, enjoyment, and finding of one's true self while staying at the location being marketed.

The results of this study also have practical implications for DMOs. Practitioners should provide a sense of uniqueness, pleasure, and connection with the authentic self of the cultural and leisure elements in the destination based on "sensations of well-being, pleasure, joy, or fun, and, at times, frustration" [107] (p. 789). Doing so can protect the sociocultural values of the local destination, subsequently leading to loyalty and satisfaction. 
Third, a major finding of this study is that residential status significantly moderates the relationship between the perception of authenticity and the destination experience. Based on these results, a significant moderating effect of authenticity dimensions and destination experience exists. As stated earlier, limited research has emphasized the moderating role of residential status in heritage tourism consumption [12,99]. The results are controversial as tourists are more likely to emphasize existential authenticity $[41,44]$, while locals perceive a lower degree of authenticity [12]. That is, the locals' destination experiences were significantly influenced by object-based authenticity, while the impact of object-based authenticity was insignificant and negative for tourists' experiences.

The current study found a distinction between tourists who sought an object to consume and locals who valued originality and history due to the different perspectives that they held concerning tourism destinations (i.e., the tourist gaze). As restoration and/or reproductions of heritage objects devalue historical and cultural experience to a certain degree, consumption of the reproduced elements of heritage could affect the locals' authentic perceptions of destination experiences, causing them to lose the originality of the destination experience [108].

Under these circumstances, if the destination experience is too heterogeneous for the tourists, then it will become difficult to attract tourists and become a consumable object. For this reason, it seems that locals tend to stage culture in the form of cultural commoditization, as the value of the destination experience is evaluated through the tourists' gaze. Prior research has provided evidence that cultural commoditization can cause social and psychological costs to locals [109], and tourism has the potential to commoditize cultural values through attaching material values to it [110]. It has been discussed that even though commoditization can transform the meaning of cultural experiences and products and/or give reproduced meanings to original meanings, it may not necessarily destroy the original meanings [8]. Instead, it is a process of struggle and incorporation to develop local cultural values through the reproduction process of culture [39].

Thus, for commoditization as it is related to sustainable destination experiences, it is necessary to enhance the awareness of researchers and practitioners on the issue of stakeholder engagement, emphasizing the importance of reaching a balance between authenticity and commoditization during heritage site development [34,111]. Practitioners should keep in mind the existence of the local user group in order to balance management strategies to enhance destination experiences in heritage tourism. Local communities should be engaged in the development and management processes since they know best about what they themselves want.

Meanwhile, even though destination experiences are influenced by existential authenticity for both groups, tourists have higher perceptions of existential authenticity in destination experiences than locals. The findings of this study are similar to previous research that has shown that experiential authenticity has more power than object-based authenticity to explain tourists' experiences [112]. The tourists perceived a higher level of existential authenticity related to destination experiences in Sanfang Qixiang, as they were motivated to visit cultural/historical attractions. These results are consistent with previous studies that showed that tourists are more likely to emphasize an existential authenticity and emotional tie [41,44]. Tourists had significant and positive impacts on their own perceptions of existential authenticity as it related to Sanfang Qixiang due to the various cultural events in Sanfang Qixiang, as the tourists did not know about the originality and genuineness of the objects in Sanfang Qixiang. However, the locals had negative impressions about the commoditization of the area as they remembered the original and genuine area.

As tourists experience tourist destinations with a tourist's gaze, DMOs need to establish destination marketing and positioning strategies that incorporate the interests of tourists. As such, tourism content needs to be created and shared to meet the needs of tourists rather than the needs of the locals. 
The study provides fresh insights into heritage tourism with regard to destination experiences based on authenticity dimensions from a residential status perspective. The results demonstrate that residential status is a significant moderator between authenticity and the destination experience. It is worth noting that this study highlighted the importance of existential authenticity as the most powerful predictor of tourists' destination experiences among the authenticity dimensions that are moderated by residential status. Moreover, this study advances the literature on the perceptions of authenticity in heritage tourism by integrating aspects of cultural heritage and local culture and examining the moderating role in the relationship between authenticity and the destination experience. To date, no research has explored the moderating effect of residential status (i.e., locals vs. tourists) on the relationship between authenticity and the destination experience. Thus, this study contributes to the existing knowledge on authenticity and emphasizes the significance of the concept in heritage tourism.

\subsection{Theoretical Implications}

First, in the Western-centric heritage tourism field, this paper adds new information in the Asian context, and the researchers hope that it will attract more attention to the development and management of heritage sites other than UNESCO destinations. Second, as an indispensable element of heritage sites, authenticity is highly related to tourist satisfaction and experience. Moreover, the addition of the locals' perceptions related to authenticity helps bridge the gap found in previous tourist-oriented studies related to authenticity in heritage tourism. The similarities and differences reported in this comparative research study should encourage more studies about locals as visitors instead of service providers. Third, that prior knowledge plays a role in the perceptions of authenticity suggests a huge research potential related to determining the function of prior knowledge in the perception process.

\subsection{Practical Implications}

This research has two important practical implications. First, the multiple-group analysis provides local tourism managers with profiles of both local visitors and tourists, showing the differences that exist in various aspects, such as use patterns, cultural backgrounds, and expectations. Second, both locals' and tourists' perception levels of object-based authenticity have been found to be lower than existential authenticity. Despite certain irreversible changes that happened during the restoration period, local tourism managers should make efforts to enhance the perception levels of existential authenticity on behalf of both groups.

\subsection{Limitations and Future Research}

This study has the following limitations. First, this research identified the antecedent and consequences of authenticity on destination experiences in Fuzhou. Thus, for external validity, further studies should apply this proposed model using different populations in different destinations so as to embrace more international views and interactions on this topic.

Second, the respondents in this study were mostly young female adults. The collected data may not represent other visitors. Additionally, the results in this study are only representative for the visitors during the sample period from April to May 2017 and may not apply to those individuals who visit Sanfang Qixiang at other times. Thus, future studies should have larger sample sizes and diverse population groups.

Third, the respondents were asked to rate the questionnaire items on a five-point Likert scale. These items were selected based on a literature review. It is possible that other aspects that were not included could have contributed to their authenticity perceptions. To increase the reliability of the research model, the authors suggest involving more measurement items for the same constructs, especially the determinant role of prior knowledge on authenticity. The addition of other variables, such as attitude and mindfulness, is also 
feasible. These aspects were not considered in this research and may allow the current model to explain the phenomenon in a more persuasive way.

Author Contributions: Writing—original draft preparation, X.L. and Y.C.; writing—review and editing, G.L.; formal analysis, W.L.; supervision, G.L. All authors have read and agreed to the published version of the manuscript.

Funding: This research received no external funding.

Acknowledgments: The data for our study came from the second author's master's thesis.

Conflicts of Interest: The authors declare no conflict of interest.

\section{Appendix A}

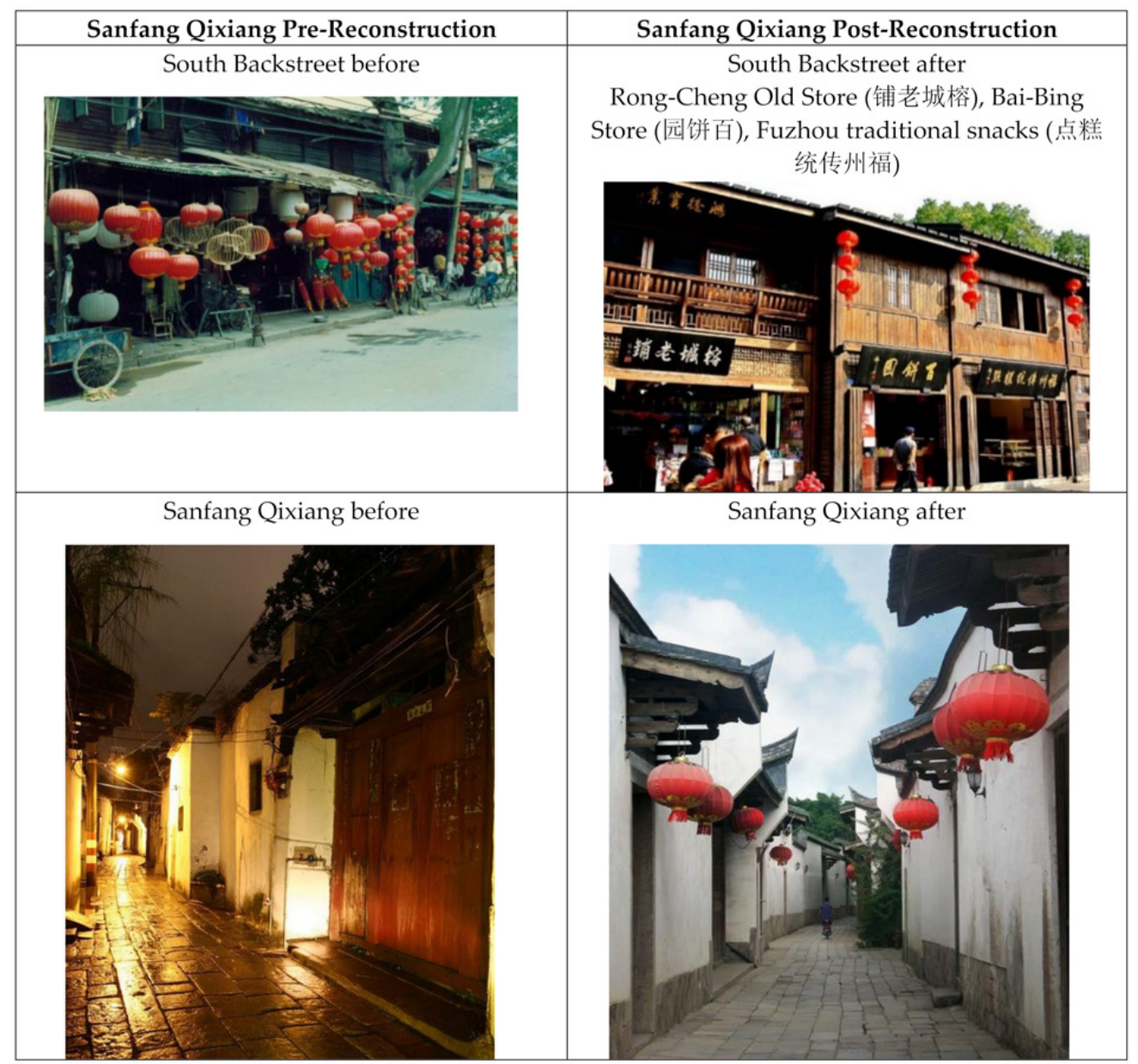

Figure A1. Cont. 


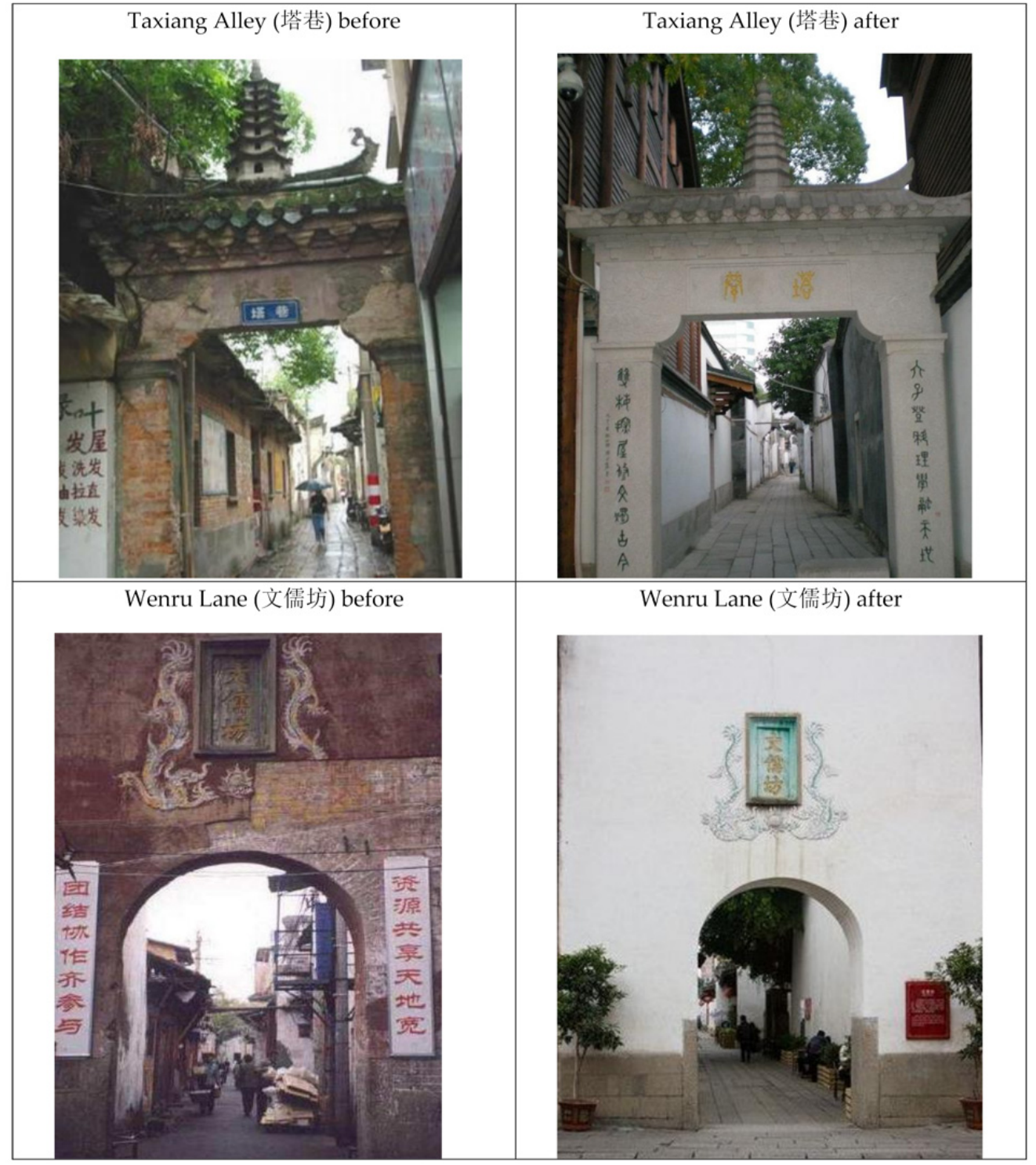

Figure A1. Photos of Sanfang Qixiang pre- and post-reconstruction.

\section{References}

1. Iossifova, D. China: Toward an integrated approach to cultural heritage preservation and economic development. CityCity Mag. 2014, 2014, 34-37.

2. $\mathrm{Su}, \mathrm{J}$. Understanding the changing intangible cultural heritage in tourism commodification: The music players' perspective from Lijiang, China. J. Tour. Cult. Chang. 2019, 17, 247-268. [CrossRef]

3. Su, L.; Swanson, S.R.; He, X. A scale to measure residents' perceptions of destination social responsibility. J. Sustain. Tour. 2020, 28, 873-897. [CrossRef]

4. Zhouzhuang: Worries about Excessive Commercialization. Available online: http://go.huanqiu.com/zhuantiyongwen/2010-04/ 784382.html (accessed on 19 April 2020).

5. The Social Benefits of Heritage. Available online: https://unesdoc.unesco.org/ark:/48223/pf0000216604 (accessed on 14 January 2020).

6. MacCannell, D. Staged authenticity: Arrangements of social space in tourist settings. Am. J. Sociol. 1973, 79, 589-603. [CrossRef]

7. Trilling, L. Sincerity and Authenticity; Harvard University Press: Cambridge, MA, USA, 1972.

8. Boorstin, D.J. The Image: A Guide to Pseudo-Events in America; Atheneum: New York, NY, USA, 1961.

9. Cohen, E. Authenticity and commoditization in tourism. Ann. Tour. Res. 1988, 15, 371-386. [CrossRef]

10. Urry, J. The Tourist Gaze: Leisure and Travel in Contemporary Societies; Sage Publications: London, UK, 1990.

11. Maoz, D. The mutual gaze. Ann. Tour. Res. 2006, 33, 221-239. [CrossRef]

12. Mura, P.; Lovelock, B. A not so little Italy? Tourist and resident perceptions of authenticity in Leichhardt, Sydney. Tour. Cult. Commun. 2009, 9, 29-48. [CrossRef]

13. Garrod, B.; Fyall, A. Managing heritage tourism. Ann. Tour. Res. 2000, 27, 682-708. [CrossRef] 
14. Poria, Y.; Airey, D.; Butler, R. Challenging the present approach to heritage tourism: Is tourism to heritage places heritage tourism? Tour. Rev. 2011, 56, 51-53. [CrossRef]

15. Timothy, D.J. The Heritage Tourist Experience: Critical Essays; Ashgate Publishing: Aldershot, UK, 2007 ; Volume 2.

16. Murphy, P.E. Tourism-A Community Approach; Springer: New York, NY, USA, 1985.

17. Choe, Y. Residents' perceptions of the social impact of the World Expo 2010 Shanghai. Master's Thesis, Purdue University, West Lafayette, IN, USA, 2011.

18. Choe, Y.; Lehto, X.; Lee, C.K. The impact of community attachment and ethnocentrism on residents' perceptions of the social impact of a mega-event. Int. J. Tour. Hosp. Res. 2019, 33, 75-86.

19. Hao, S.; Yuan, S. Discussion on the sustainable development of cultural tourism in the historic district of Sanfang Qixiang in Fuzhou. J. Fuqing Branch Fujian Norm. Univ. 2009, 6, $23-27$.

20. Sun, F. Research on cultural heritage protection and development countermeasures from the perspective of sustainable development: A case study of Three Lanes and Seven Alleys in Fuzhou. Fujian Forum Human. Soc. Sci. 2011, 12, 86-92.

21. Gurira, N.A.; Ngulube, P. Using contingency valuation approaches to assess sustainable cultural heritage tourism use and conservation of the outstanding universal values (OUV) at Great Zimbabwe World Heritage Site in Zimbabwe. Procedia Soc. Behav. Sci. 2016, 225, 291-302. [CrossRef]

22. Jaafar, M.; Noor, S.M.; Rasoolimanesh, S.M. Perception of young local residents toward sustainable conservation programmes: A case study of the Lenggong World Cultural Heritage Site. Tour. Manag. 2015, 48, 154-163. [CrossRef]

23. You, W.B.; He, D.J.; Hong, W.; Liu, C.; Wu, L.Y.; Ji, Z.R.; Xiao, S.H. Local people's perceptions of participating in conservation in a heritage site: A case study of the Wuyishan Scenery District cultural and natural heritage site in South eastern China. Nat. Resour. Forum 2014, 38, 296-307. [CrossRef]

24. Graham, B.; Ashworth, G.J.; Tunbridge, J.E. A Geography of Heritage: Power, Culture and Economy; Arnold: London, UK, 2000.

25. Poria, Y.; Biran, A.; Reichel, A. Visitors' preferences for interpretation at heritage sites. J. Travel Res. 2009, 48, 92-105. [CrossRef]

26. Wu, T.C.; Xie, P.F.; Tsai, M.C. Perceptions of attractiveness for salt heritage tourism: A tourist perspective. Tour. Manag. 2015, 51, 201-209. [CrossRef]

27. Liang, Z.X.; Hui, T.K. Residents' quality of life and attitudes toward tourism development in China. Tour. Manag. 2016, 57, 56-67. [CrossRef]

28. MacCannell, D. Tourist agency. Tour. Stud. 2001, 1, 23-37. [CrossRef]

29. Poon, A. Competitive strategies for a 'New Tourism'. In Classic Reviews in Tourism; Cooper, C.P., Ed.; Channel View Publications: Clevedon, UK, 2003; pp. 130-142.

30. Today's Word: Heritage Tourism. Available online: https://savingplaces.org/stories/preservation-glossary-todays-wordheritage-tourism\#.X38Tt5MzaRZ (accessed on 5 October 2020).

31. Xing, H.B.; Marzuki, A.; Razak, A.A. Conceptualizing a sustainable development model for cultural heritage tourism Asia. Theor. Empir. Res. Urban Manag. 2013, 8, 51-66.

32. Hoppen, A.; Brown, L.; Fyall, A. Literary tourism: Opportunities and challenges for the marketing and branding of destinations? J. Destin. Mark. Manag. 2014, 3, 37-47. [CrossRef]

33. Timothy, D.J. Contemporary cultural heritage and tourism: Development issues and emerging trends. Public Archaeol. 2014, 13, 30-47. [CrossRef]

34. McKercher, B.; du Cros, H. Cultural Tourism: The Partnership between Tourism and Cultural Heritage Management; Haworth Press: Binghamton, NY, USA, 2002.

35. Cohen, E.; Cohen, S.A. Current sociological theories and issues in tourism. Ann. Tour. Res. 2012, 39, 2177-2202. [CrossRef]

36. Park, H.Y. Heritage tourism: Emotional journeys into nationhood. Ann. Tour. Res. 2010, 37, 116-135. [CrossRef]

37. Osborne, B.S.; Kovacs, J.F. Cultural tourism: Seeking authenticity, escaping into fantasy, or experiencing reality. Choice 2008, 45 , 927-937. [CrossRef]

38. Goulding, C. The commodification of the past, postmodern pastiche, and the search for authentic experiences at contemporary heritage attractions. Eur. J. Mark. 2000, 34, 835-853. [CrossRef]

39. Halewood, C.; Hannam, K. Viking heritage tourism: Authenticity and commodification. Ann. Tour. Res. 2001, 28, 565-580. [CrossRef]

40. Choe, Y.; Schuett, M.A.; Sim, K. An analysis of first-time and repeat visitors to Korean national parks from 2007 and 2013. J. Mt. Sci. 2017, 14, 2527-2539. [CrossRef]

41. Richards, G. Cultural Tourism: Global and Local Perspectives; Haworth Press: Binghamton, NY, USA, 2007.

42. Tourism Statistics of 2016 and Prediction for 2017. Available online: http:/ / www.ctaweb.org/html/2017-2/2017-2-24-9-10-97907. html (accessed on 2 February 2017).

43. Heitmann, S. Tourist behavior and tourism motivation. In Research Themes for Tourism; Robinson, P., Heitmann, S., Dieke, P.U.C., Eds.; CABI: Cambridge, MA, USA, 2011; pp. 31-44.

44. Wang, N. Rethinking authenticity in tourism experience. Ann. Tour. Res. 1999, 26, 349-370. [CrossRef]

45. Dyson, P. Slum tourism: Representing and interpreting 'reality' in Dharavi, Mumbai. Tour. Geogr. 2012, 14, 254-274. [CrossRef]

46. Boyd, S. Cultural and heritage tourism in Canada: Opportunities, principles and challenges. Tour. Hosp. Res. 2002, 3, 211-233. [CrossRef]

47. Chhabra, D.; Healy, R.; Sills, E. Staged authenticity and heritage tourism. Ann. Tour. Res. 2003, 30, 702-719. [CrossRef] 
48. Chen, C.F.; Chen, P.C. Another look at the heritage tourism experience. Ann. Tour. Res. 2013, 41, 236-240. [CrossRef]

49. Belhassen, Y.; Caton, K.; Stewart, W.P. The search for authenticity in the pilgrim experience. Ann. Tour. Res. 2008, 35, 668-689. [CrossRef]

50. Rittichainuwat, B.; Laws, E.; Scott, N.; Rattanaphinanchai, S. Authenticity in screen tourism: Significance of real and substituted screen locations. J. Hosp. Tour. Res. 2018, 42, 1274-1294. [CrossRef]

51. Woodside, A.G.; Martin, D. Introduction: The tourist gaze 4.0: Uncovering non-conscious meanings and motivations in the stories tourists tell of trip and destination experiences. Int. J. Tour. Anthropol. 2015, 4, 1-12. [CrossRef]

52. Moyle, B.D.; Weiler, B.; Croy, G. Visitors' perceptions of tourism impacts: Bruny and Magnetic Islands, Australia. J. Travel Res. 2013, 52, 392-406. [CrossRef]

53. Crompton, J.L. Motivations for pleasure vacation. Ann. Tour. Res. 1979, 6, 408-424. [CrossRef]

54. Lee, G.; O'Leary, J.T.; Lee, S.H.; Morrison, A. Comparison and contrast of push and pull motivational effects on trip behavior: An application of a multinomial logistic regression model. Tour. Anal. 2002, 7, 89-104. [CrossRef]

55. Kolar, T.; Zabkar, V. A consumer-based model of authenticity: An oxymoron or the foundation of cultural heritage marketing? Tour. Manag. 2010, 31, 652-664. [CrossRef]

56. Ra, D.S. Korean cultural inheritances from the perspective of tourism therapy. Kyoungju Hist. Soc. 2011, 33, 87-106.

57. Bryce, D.; Curran, R.; O'Gorman, K.; Taheri, B. Visitors' engagement and authenticity: Japanese heritage consumption. Tour. Manag. 2015, 46, 571-581. [CrossRef]

58. Lee, S.; Phau, I.; Hughes, M.; Li, Y.F.; Quintal, V. Heritage tourism in Singapore Chinatown: A perceived value approach to authenticity and satisfaction. J. Travel Tour. Mark. 2016, 33, 981-998. [CrossRef]

59. Middleton, V.T.C.; Clarke, J.R. Marketing in Travel and Tourism; Butterworth-Heinemann: Oxford, UK, 2001.

60. McIntosh, A.J. Tourists' appreciation of Maori culture in New Zealand. Tour. Manag. 2004, 25, 1-15. [CrossRef]

61. Gnoth, J. Tourism motivation and expectation formation. Ann. Tour. Res. 1997, 24, 283-304. [CrossRef]

62. Khanom, S.; Moyle, B.; Scott, N.; Kennelly, M. Host-guest authentication of intangible cultural heritage: A literature review and conceptual model. J. Herit. Tour. 2019, 14, 396-408. [CrossRef]

63. Alba, J.W.; Hutchinson, J.W. Dimensions of consumer expertise. J. Consum. Res. 1987, 13, 411-454. [CrossRef]

64. Gursoy, D.; McCleary, K.W. An integrative model of tourists' information search behavior. Ann. Tour. Res. 2004, 31, 353-373. [CrossRef]

65. Ratchford, B. The economics of consumer knowledge. J. Consum. Res. 2001, 27, 397-411. [CrossRef]

66. Huang, L.; Gursoy, D.; Xu, H. Impact of personality traits and involvement on prior knowledge. Ann. Tour. Res. 2014, 48, 42-57. [CrossRef]

67. Brucks, M. The effects of product class knowledge on information search behavior. J. Consum. Res. 1985, 12, 1-16. [CrossRef]

68. Lau, R.W. Revisiting authenticity: A social realist approach. Ann. Tour. Res. 2010, 37, 478-498. [CrossRef]

69. Connell, J. The continuity of custom? Tourist perceptions of authenticity in Yakel Village, Tanna, Vanuatu. J. Tour. Cult. Chang. 2007, 5, 71-86. [CrossRef]

70. Yang, L.; Wall, G. Authenticity in ethnic tourism: Domestic tourists' perspectives. Curr. Issues Tour. 2009, 12, 235-254. [CrossRef]

71. Cohen, E. Rethinking the sociology of tourism. Ann. Tour. Res. 1979, 6, 18-35. [CrossRef]

72. Uriely, N. The tourist experience: Conceptual developments. Ann. Tour. Res. 2005, 32, 199-216. [CrossRef]

73. Pine, B.J.; Gilmore, J.H. Welcome to the experience economy. Harv. Bus. Rev. 1998, 76, 97-105. [PubMed]

74. Song, H.; Kim, M.; Choe, Y. Structural relationships among mega-event experiences, emotional responses, and satisfaction: Focused on the 2014 Incheon Asian Games. Curr. Issues Tour. 2019, 22, 575-581. [CrossRef]

75. Bello, D.C.; Etzel, M.J. The role of novelty in the pleasure travel experience. J. Travel Res. 1985, 24, 20-26. [CrossRef]

76. Shoval, N.; Schvimer, Y.; Tamir, M. Real-time measurement of tourists' objective and subjective emotions in time and space. J. Travel Res. 2018, 57, 3-16. [CrossRef]

77. Yeoman, I.; Brass, D.; McMahon-Beattie, U. Current issue in tourism: The authentic tourist. Tour. Manag. 2007, $28,1128-1138$. [CrossRef]

78. Grayson, K.; Martinec, R. Dimensions of consumer expertise. J. Consum. Res. 2004, 31, 296-312. [CrossRef]

79. Leigh, T.W.; Peters, C.; Shelton, J. The consumer quest for authenticity: The multiplicity of meanings within the MG subculture of consumption. J. Acad. Mark. Sci. 2006, 34, 481-493. [CrossRef]

80. Poria, Y.; Butler, R.; Airey, D. The core of heritage tourism. Ann. Tour. Res. 2003, 30, 238-254. [CrossRef]

81. Prentice, R. Experiential cultural tourism: Museums \& the marketing of the new romanticism of evoked authenticity. Mus. Manag. Curatorsh. 2001, 19, 5-26.

82. Ramkissoon, H.; Uysal, M.S. The effects of perceived authenticity, information search behaviour, motivation and destination imagery on cultural behavioural intentions of tourists. Curr. Issues Tour. 2011, 14, 537-562. [CrossRef]

83. Gupta, V.; Khanna, K.; Gupta, R.K. A study on the street food dimensions and its effects on consumer attitude and behavioural intentions. Tour. Rev. 2018, 73, 374-388. [CrossRef]

84. Ji, M.; Wong, I.A.; Eves, A.; Scarles, C. Food-related personality traits and the moderating role of novelty-seeking in food satisfaction and travel outcomes. Tour. Manag. 2016, 57, 387-396. [CrossRef]

85. Gupta, V.; Sajnani, M. A study on the influence of street food authenticity and degree of their variations on the tourists' overall destination experiences. Br. Food J. 2020, 122, 779-797. [CrossRef] 
86. Zhang, H.; Seo, T.Y. A research on structural relationships between cross-cultural awareness, authenticity and tourist experience of Chinese tourists: Centered on Korean world cultural heritage travel destination. Korean J. Hosp. Tour. 2014, 29, 201-223.

87. Eco, U. Travels in Hyperreality; Picador: London, UK, 1986.

88. Duncan, J.S. The social construction of unreality: An interactionist approach to the tourist's cognition of environment. In Humanistic Geography: Prospects and Problems; Ley, D., Samuels, M.S., Eds.; Maaroufa Press: Chicago, IL, USA, 1978; pp. 269-282.

89. Chen, L.; Li, J.; Guan, R. Analysis of the protection process of the Three Lanes and Seven Alleys Historic District in Fuzhou and its enlightenment. Huazhong Archit. 2015, 33, 181-184.

90. Luo, R.; Chen, Y.; Sun, Y. Investigation of changes before and after the transformation of Sanfang Qixiang and its impact research. Sci. Fortune 2012, 10, 16-17.

91. Yin, X.; Zheng, X. Research on the cultural perception of tourists in Sanfang Qixiang based on network text analysis. J. Beijing Int. Stud. Univ. 2015, 37, 62-66.

92. Lin, X. Residents and domestic tourists' perceptions of authenticity in a heritage site: The Three Lanes and Seven Alleys in Fuzhou, China. Master's Thesis, Kyung Hee University, Seoul, Korea, 2017.

93. History Meets the Present in Fuzhou's Ancient Neighborhood. Available online: http://www.chinadaily.com.cn/china/ culturaltouralongsilkroad/2015-11/18/content_22481308.htm (accessed on 5 October 2020).

94. Su, M.M.; Wall, G. Exploring the shared use of world heritage sites: Residents and domestic tourists' use and perceptions of the summer palace in Beijing. Int. J. Tour. Res. 2015, 17, 591-601. [CrossRef]

95. Bentler, P.M.; Wu, E.J. EQS for Windows User's Guide; Multivariate Software: Encino, CA, USA, 1995.

96. Anderson, J.C.; Gerbing, D.W. Structural equation modeling in practice: A review and recommended two-step approach. Psychol. Bull. 1988, 103, 411-423. [CrossRef]

97. Anderson, J.C.; Gerbing, D.W. Assumptions and comparative strengths of the two-step approach: Comment on Fornell and Yi. Sociol. Methods Res. 1992, 20, 321-333. [CrossRef]

98. Naoi, T. Visitors' evaluation of a historical district: The roles of authenticity and manipulation. Tour. Hosp. Res. 2004, 5, 45-63. [CrossRef]

99. Kerstetter, D.; Cho, M.H. Prior knowledge, credibility and information search. Ann. Tour. Res. 2004, 31, 961-985. [CrossRef]

100. Fornell, C.; Larcker, D.F. Structural equation models with unobservable variables and measurement error: Algebra and statistics. J. Mark. Res. 1981, 18, 382-388. [CrossRef]

101. Hair, J.F.; Black, W.C.; Babin, B.J.; Anderson, R.E. Multivariate Data Analysis; Cengage Learning: Hampshire, UK, 2019.

102. Woo, J.P. The Concept and Understanding of Structural Equation Model; Hannarae: Seoul, Korea, 2012.

103. Kline, R.B. Software review: Software programs for structural equation modeling: Amos, EQS, and LISREL. J. Psychoeduc. Assess. 1998, 16, 343-364. [CrossRef]

104. Lee, Y.K. Impact of government policy and environment quality on visitor loyalty to Taiwan music festivals: Moderating effects of revisit reason and occupation type. Tour. Manag. 2016, 53, 187-196. [CrossRef]

105. González, M.V. Intangible heritage tourism and identity. Tour. Manag. 2008, 29, 807-810. [CrossRef]

106. Turner, G. Making It National: Australian Nationalism and Popular Culture; Allen \& Unwin: Sydney, Australia, 1994.

107. Daniel, Y.P. Tourism dance performances authenticity and creativity. Ann. Tour. Res. 1996, 23, 780-797. [CrossRef]

108. Kuon, V. The pursuit of authenticity in tourist experiences: The case of Siem Reap-Angkor, Cambodia. Ph.D. Dissertation, Lincoln University, Oakland, CA, USA, 2011.

109. Jarvenpa, R. Commoditization versus cultural integration: Tourism and image building in the Klondike. Arct. Anthropol. 1994, 31, 26-46.

110. Culture, Commodification and Tourism. Available online: http://www.ipcs.org/issue_briefs/issue_brief_pdf/IB238 -LadakhFiles-TashiLundup-Tourism.pdf (accessed on 20 June 2019).

111. Choe, Y.; Schuett, A. Stakeholders' perceptions of social and environmental changes affecting Everglades National Park in South Florida. Environ. Dev. 2020, 35, 100524. [CrossRef]

112. Moutinho, L.; Vargas-Sanchez, A. Strategic Management in Tourism; CABI: Boston, MA, USA, 2018. 